\title{
LA POLÍTICA ENERGÉTICA: UNA ASIGNATURA PENDIENTE A NIVEL PAÍS
}

\author{
Pedro Maldonado
}




\section{PEDRO MALDONADO}

Ingeniero Civil Electricista de la Universidad de Chile. MSc. Université du Québec à Montréal, Canadá. Se desempeña como profesor adjunto tanto en la Facultad de Ciencias Físicas y Matemáticas de la Universidad de Chile (ad honorem), como en el Instituto de Asuntos Públicos (ad honorem) de la misma universidad. Actualmente, es subdirector del Programa de Estudios e Investigación en Energía. 


\section{LA POLÍTICA ENERGÉTICA: UNA ASIGNATURA PENDIENTE A NIVEL PAÍS}

\section{INTRODUCCIÓN}

El presente artículo pretende contribuir al debate público sobre las políticas que han orientado el desarrollo energético nacional, las consecuencias de ellas y cuáles podrían ser las propuesta de reforma para reorientar el sistema energético desde la perspectiva del desarrollo sustentable ${ }^{1}$. A lo largo del mismo, se abordará la importancia del contexto internacional en la definición de las políticas energéticas de un país extraordinariamente dependiente de las fuentes de energía convencional como es el nuestro, el funcionamiento de un sistema eléctrico determinado por treinta años de una política centrada en las decisiones del sector privado, y un Estado sin la capacidad legal de articular el desarrollo eléctrico. Todo lo anterior ha conducido a un sistema eléctrico vulnerable, dependiente, sucio, carbonizado, altamente concentrado, caro e inequitativo, lo que no puede estar más lejos de un desarrollo sustentable.

Las propuestas que aquí se incluyen se han nutrido de un debate que incorpora a distintos sectores de la sociedad, quienes, desde una perspectiva ciudadana, técnica y parlamentaria, integran en su visión del desarrollo eléctrico, las variables económicas, socioambientales, de desarrollo territorial y regional, y de equidad. La síntesis que el autor ha ido construyendo a partir de su larga experiencia en el tema se ha enriquecido con el aporte de múltiples actores del mundo ciudadano, dando como resultado un conjunto de medidas para reformar en profundidad el marco regulatorio, transformar la eficiencia energética y las energías renovables en opciones estratégicas de la política de desarrollo eléctrico, incorporar los costos externos de una contaminación que no pagan los responsables de las emisiones vinculadas a la conversión y uso de la energía, sino que la sociedad en su conjunto, y sugerir formas de participación ciudadana a nivel nacional, regional y local.

El artículo concluye planteando que los cambios propuestos deben ser la resultante de un proceso participativo real, informado y vinculante que apunte a definir los lineamientos de la nueva política energética y que, en el caso de proyectos de impacto nacional o regional, la participación ciudadana se exprese desde las primeras etapas del proyecto.

1. Si bien las deficiencias de la política energética nacional atañen a la conversión y uso de la energía, en este artículo la reflexión se centra en las políticas, o falta de ellas, que han condicionado la evolución del sistema eléctrico chileno y que han estado en el centro del debate nacional en los últimos años. 


\section{EL CONTEXTO INTERNACIONAL Y SU INCIDENCIA EN LA SITUACIÓN ENERGÉTICA NACIONAL, ACTUAL Y FUTURA}

Lo central para entender el contexto internacional de la energía es la tremenda inequidad energética que afecta a una parte importante del planeta. Para ello, basta entregar algunos datos que la reflejan. En primer lugar, WEO 2010² señala que en el mundo "1.400 millones de personas (más del 20\% de la población mundial) no tienen acceso a la energía eléctrica en sus hogares, y que 2.700 millones (cerca de un $40 \%$ de la población total) usan biomasa para la cocción de sus alimentos". A ello, se agrega que, al año 2009, China tenía un consumo per cápita de electricidad del orden de un 80\% del consumo chileno, y que el consumo per cápita de la India era un 18\% del consumo nacional. Esta situación de inequidad energética a nivel mundial es insostenible, y es lógico pensar que ella se deberá revertir en un plazo breve, las tasas de crecimiento del consumo de energía de China y la India así lo indican. Cabe, entonces, preguntarse: cómo afectará ello a la demanda y a los precios de los combustibles, y si el planeta será capaz de resistir la presión sobre los recursos energéticos fósiles y sobre el medio ambiente. Todo ello llevará con certeza a modificar los patrones convencionales de consumo y la estructura de las fuentes de energía, enfatizando el uso de las Energías Renovables No Convencionales (ERNC).

En este contexto, sorprende que las autoridades nacionales, especialistas y medios de comunicación, normalmente adscritos a la mantención del statu quo, no solo ignoren lo anterior, sino que además planteen que la volatilidad de los mercados energéticos sea coyuntural y que, tan pronto se alivien las tensiones en el Medio Oriente, la situación volverá a ser la "normal"; luego, no es necesario explotar otras fuentes energéticas no convencionales, ya que ellas son más caras, y lo serán aún más cuando los mercados se regularicen. Sin embargo, la experiencia parece indicar otra cosa. Por lo pronto, el petróleo sigue cotizándose en torno a US\$ 100/barril, a pesar de que el mundo desarrollado arrastra por bastante tiempo una crisis económica, que en algunos casos corresponde a una recesión, y que China ha reducido sus tasas históricas de crecimiento 3 .

Algunos indicadores parecen mostrar que dicha volatilidad corresponde a una situación estructural. Por lo pronto, la IEA se suma a quienes han destacado la gravedad del problema, recurriendo al concepto del Peak oil ${ }^{4}$, que se traduce en una curva de producción de petróleo que habría alcanzado, o estaría alcanzando, el máximo de producción y que, a partir de ese punto, la producción mundial se iría inexorablemente reduciendo ${ }^{5}$.

\footnotetext{
2. International Energy Agency (IEA), World Energy Outlook 2010, spanish summary.

3. Es probable que una vez superada la crisis, el precio del petróleo supere largamente el precio actual.

4. Conocido originalmente como el "cenit de Hubbert". Los partidarios de esta teoría no afirman que el petróleo se vaya a acabar, sino que el equilibrio entre la oferta y la demanda se logrará mediante un incremento sustancial del aporte de las ERNC y la eficiencia energética, y/o un incremento sustantivo de los precios de los combustibles fósiles.

5. Ello no ignora el potencial aporte de los petróleos pesados y del gas natural no convencional, ambos con sus problemas específicos.
} 
Sin recurrir a la curva mencionada, el Gráfico 1 reforzaría la postura de quienes señalan que el problema es más bien estructural. En efecto, dicho gráfico permite visualizar que a partir de 1981 la explotación supera sistemáticamente los descubrimientos de nuevos yacimientos.

\section{Gráfico 1}

EVOLUCIÓN DE LOS DESCUBRIMIENTOS Y EXPLOTACIÓN DEL PETRÓLEO

(en miles de millones de barriles/año)

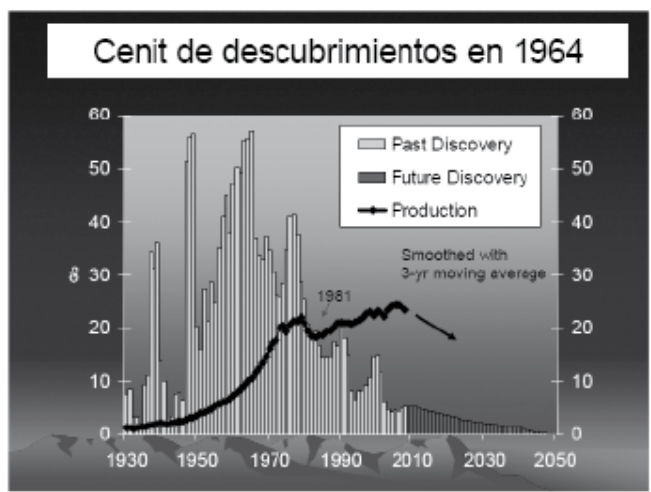

C. Campbell; ASPO Berlín, mayo 2009

Fuente: Enrique Wittwer, Seminario Mes de la Energía, Colegio de Ingenieros, 2010.

Hasta el año 2010, los valores de ambos parámetros son estadísticos y, desde esa fecha, el gráfico se construyó a partir de estimaciones basadas en previsiones de producción y nuevos desarrollos geológicos.

El Gráfico 2 muestra la evolución del precio del petróleo presentada en el Informe Técnico Definitivo (ITD) para la fijación de precio de nudo del SIC (abril 2012).

\section{Gráfico 2}

EVOLUCIÓN DEL PRECIO DEL PETRÓLEO WTI

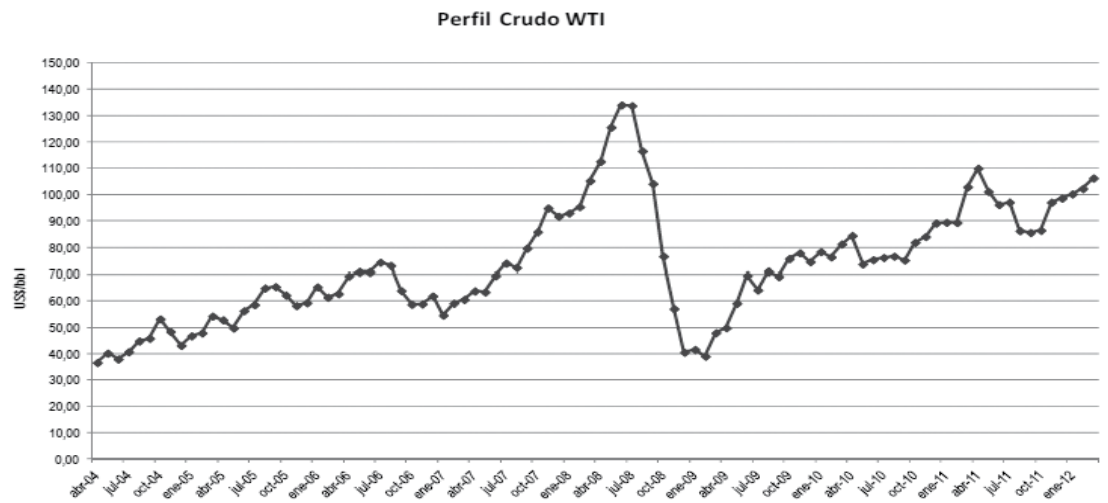

Fuente: CNE. Informe Técnico Definitivo (ITD) para la fijación del precio de nudo, abril 2012. 
A su vez, el mercado del gas natural y el carbón han seguido la tendencia del petróleo, manteniendo su mayor competitividad en aquellos mercados en que ellos pueden sustituir al petróleo. Esta situación se ha reflejado en el mercado nacional no solo en lo que respecta a la evolución del mercado internacional del petróleo, sino que también en la de los otros combustibles fósiles.

En efecto, el precio del carbón se incrementó sostenidamente desde los US\$30/ton que costaba en el año 2003 a US\$ 60/ton entre el 2004 y 2007. De acuerdo con la fijación de precios de la CNE para abril del 2012, las empresas pagaron desde US\$ 90/ton a más de US\$ 120/ton. En relación al gas natural, en la fijación de precios de nudo del 2004 su valor alcanzaba a US\$ 1,6/MMBTU, al año 2009 el valor era de US\$ 9,51/MMBTU, y en abril del año 2012 las empresas cancelaron entre US\$ 15,4 a 17,4/MMBTU 6

Tomando en consideración los antecedentes anteriores, es posible afirmar que el período de bonanza, es decir, de precios bajos de la energía, terminó hace algunos años y que es difícil que retorne a los niveles de precios previos, más aún si la presión por generalizar los impuestos al carbono adquiere cada vez más fuerza, incluso en países de menor nivel de desarrollo relativo o en transición ${ }^{7}$.

El contexto internacional incorpora la protección medioambiental con mucha fuerza, si bien en las últimas décadas del siglo pasado la contaminación atmosférica concitaba la atención y preocupación de las autoridades de los países desarrollados, en los 90, el centro de su preocupación se desplaza hacia el cambio climático y es muy probable que este sea el gran tema ambiental del siglo XXI. Dicho lo anterior, la evaluación de las políticas públicas en el campo de la energía no debe perder de vista el contexto internacional y nacional, más aún en el caso de un país de economía abierta.

Antes de entrar en el tema objeto de este artículo, conviene clarificar un concepto que, desgraciadamente, ha sido erróneamente introducido por las autoridades públicas y que se ha generalizado a través de los medios de comunicación, induciendo incluso a su aceptación por parte de algunos especialistas. Durante estos últimos años, se ha utilizado los términos "matriz energética" o "política energética" para referirse a la estructura del parque de generación eléctrica o a las normativas y lineamientos que definen el desarrollo eléctrico del país, desconociendo que la electricidad representa menos del 20\% del consumo final de energía ${ }^{8}$.

6. Las proyecciones de abril de 2012, presentadas en el ITD, muestran una caída del GNL a US\$7,63/ MMBTU para el año 2013, valor que se incrementa paulatinamente para alcanzar los US\$ 10/MMBU a partir del 2020, lo que parece extraño, salvo que se suponga que el GN no convencional provocará una caída importante del mercado internacional, basado en costos actuales de explotación muy bajos. Sin embargo, cabe preguntarse qué razones tendrían los productores en ofrecer su gas a un precio tan reducido y no utilizar sus ventajas relativas en beneficio propio, o si no deberán considerarse costos de base superiores a los actuales para enfrentar los problemas ambientales que han sido denunciados recientemente.

7. Ello podría ocurrir en Chile, de materializarse lo propuesto por el presidente Piñera: impuesto a los "males".

8. Ministerio de Energía, Sistema de Información Estadístico, Balance Nacional de Energía 2011. 
Aceptado lo anterior, este artículo se centrará, como se señalara previamente, en el análisis de la política de desarrollo eléctrico y de sus consecuencias, debido a que el tema ha estado en el centro del debate en los últimos años, y a que el abastecimiento de combustibles fósiles está regido básicamente por el mercado internacional, del que Chile es un "tomador de precios"; reconociendo que las políticas que condicionan el uso final de los combustibles son igualmente controvertibles, a pesar de lo cual el artículo incluirá algunas menciones acotadas a dichos usos finales en los casos que corresponda.

\section{FUNCIONAMIENTO ACTUAL DEL SISTEMA ELÉCTRICO CHILENO}

El funcionamiento del sistema eléctrico está regido fundamentalmente por el DFL $\mathrm{N}^{\circ} 1$ de $1982^{9}$, que desintegró los segmentos de generación, transmisión y distribución, definió el esquema tarifario y entregó al sector privado la facultad de definir dónde, cómo y cuándo desarrollar los proyectos de generación eléctrica, asignando a un Estado subsidiario el rol regulador y fiscalizador ${ }^{10}$. Conviene destacar que, originalmente, se consideró que la regulación y exigencias de inversión se limitaran al segmento de distribución, la transmisión solo era mencionada para los efectos de fijación de precios y la generación no era sometida a ninguna exigencia regulatoria, ya que se consideraba, y se sigue considerando por algunos, que en este segmento la competencia se da en forma "natural" y, como mencionara un ministro de Energía, la mejor regulación es la competencia. Más adelante se mostrará cuán lejos de la realidad se encuentran estos planteamientos.

La participación del Estado en el mercado eléctrico se manifiesta, en parte importante, en la fijación de los precios de nudo ${ }^{11}$, y el instrumento utilizado es el Plan de Obras elaborado por la Comisión Nacional de Energía (CNE). Este se define en función de las características de las centrales y los costos de inversión, operación y mantención de los proyectos informados por las empresas generadoras. En base a esta información, la CNE simula un programa indicativo cuyo objetivo es minimizar los costos totales (a valor presente) para los usuarios. Este instrumento, al definir los precios de la energía, sirve de señal para la inversión del sector privado; sin embargo, este último no está obligado a concretar las inversiones que ellos informaron a la CNE y que dieron origen al Plan de Obras.

9. Ministerio de Minería, DFL No 1 del 13 de septiembre de 1982.

10. Los proyectos eléctricos, como todo proyecto de envergadura, deben ser presentados al Sistema de Evaluación de Impacto Ambiental (SEIA), y aprobado en esta instancia. El SEIA no ha estado exento de críticas, como se verá más adelante.

11. La Comisión Nacional de Energía determina semestralmente los precios de nudo, e informa de estos al Ministerio de Economía, quien procede a su fijación y publicación en el Diario Oficial. El precio de nudo tiene dos componentes: el precio básico de la energía (promedio en el tiempo de los costos marginales de energía del sistema, operando al mínimo costo actualizado de operación y racionamiento para el período de estudio); y el precio básico de la potencia de punta (costo marginal anual de incremento de la capacidad instalada del sistema eléctrico, considerando las unidades generadoras más económicas, determinadas para suministrar potencia adicional durante las horas de demanda máxima anual del sistema eléctrico, más el margen teórico de reserva de potencia del sistema eléctrico). 
Al no tener el Estado la capacidad constitucional para articular el desarrollo eléctrico, la regulación vigente ha ido consolidando un "desarrollo eléctrico" cada vez más sucio y carbonizado, vulnerable, dependiente, concentrado, caro y marcado por agudos conflictos socioambientales. La matriz eléctrica ha ido variando a lo largo del tiempo en función de las visiones de rentabilidad de corto plazo, y es así cómo, en un período breve de tiempo, ella ha pasado de ser básicamente hidroeléctrica a privilegiar el uso del gas natural en los proyectos que se desarrollaron desde fines de los 90 hasta medidos de los $2000^{12}$, para adoptar, con posterioridad a la crisis de abastecimiento del gas natural, como opción "indiscutida" el carbón. En cada oportunidad, se trata de identificar cuál es la "solución", pregunta que obviamente no tiene una respuesta única.

En los párrafos que siguen, se resumen las razones que conducen a los juicios esbozados en los párrafos anteriores, y que permiten concluir que el mal llamado "desarrollo" eléctrico chileno dista mucho de constituir un ejemplo de desarrollo sustentable ${ }^{13}$.

\section{VULNERABILIDAD DEL SISTEMA ELÉCTRICO CHILENO}

El sistema energético nacional es extraordinariamente dependiente de los combustibles fósiles importados, tal como se refleja en el Gráfico 3, lo que contribuye a su vulnerabilidad al incorporar al abastecimiento local la extremada volatilidad de los mercados internacionales de dichos combustibles y, más aún, la incertidumbre de su aprovisionamiento ${ }^{14}$.

\section{Gráfico 3}

GRADO DE DEPENDENCIA DEL SISTEMA ENERGÉTICO NACIONAL, 2011

\section{$\%$ importación sobre consumo total}

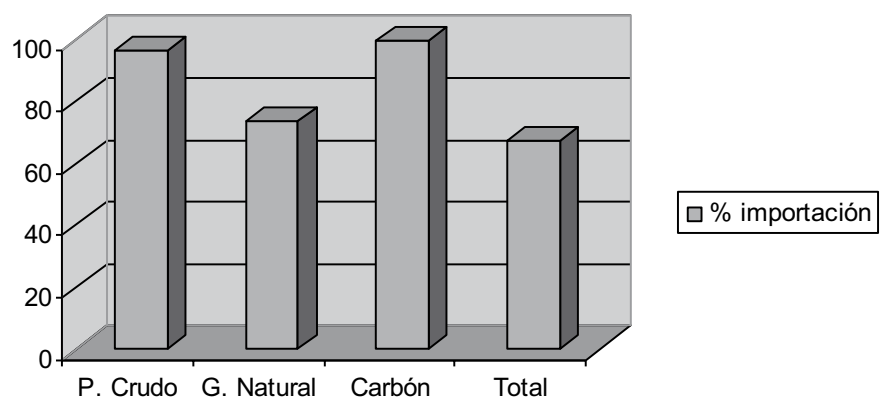

Fuente: Ministerio de Energía, Balance Nacional de Energía (BNE) 2012.

12. De acuerdo con los BNE de la CNE, el GN representó en 1998 un 20,2\% de la matriz eléctrica, y en el 2004 un $36,1 \%$.

13. Si bien un desarrollo sustentable del sector energía no resuelve todos los problemas de la sustentabilidad del desarrollo, no cabe duda que contribuye a este último objetivo.

14. Baste recordar la crisis de abastecimiento de gas natural desde Argentina o las incertidumbres que generan, al abastecimiento mundial de petróleo, las amenazas de cierre del estrecho de Ormuz. En el 2009, un 33\% del petróleo transportado marítimamente pasó por ese estrecho. 
Prácticamente, la totalidad del petróleo crudo y carbón que consume Chile proviene de importaciones, incluso las cifras de una menor dependencia relativa del gas natural son engañosas, ya que casi la totalidad de la producción local de gas natural se consume como materia prima industrial -por la firma Metanex-y, por ende, no se utiliza como energético en el país. Aceptando la simplificación estadística señalada, el abastecimiento nacional de energía primaria alcanza a un $32,4 \%$ y corresponde en un alto porcentaje a la leña, la que representa prácticamente un 20\% del consumo de energía primaria, siendo utilizada, además, en forma primitiva ${ }^{15}$.

La vulnerabilidad del sistema se hace más dramática si se considera la insuficiente inversión realizada en ampliar la capacidad de generación, problema que se arrastra desde fines de los años 90. Esta situación se puede graficar al analizar la brecha entre la potencia firme y la demanda máxima. Si bien, como se desprende del gráfico $\mathrm{N}^{\circ} 4$, la capacidad instalada ha crecido en el período, la brecha mencionada es preocupante, ya que implica un riesgo real de racionamiento como ocurriera en los años 1998-1999. Sin ir muy lejos, en agosto del 2008, el ministro de Energía reconoció que en mayo de 2008 estuvo a punto de dictar un decreto de racionamiento ${ }^{16}$, lo que no ocurrió debido a una mejora sustantiva de las condiciones meteorológicas, que incrementó la oferta hidroeléctrica; sin embargo, ello no fue óbice para que se hayan dictado decretos preventivos de racionamiento en los años 2008, 2010, 2011 y 2012 ${ }^{17}$. La fragilidad del sistema se ha traducido en múltiples fallas que han dejado sin energía, por períodos prolongados, a varias regiones. Ello ha sido ocasionado por salidas de servicio de elementos claves para el funcionamiento del sistema: centrales, transformadores de poder y líneas de transmisión ${ }^{18}$. Parece increíble que, a pesar del consenso técnico y las normativas aprobadas, el sistema de transmisión troncal no haya adoptado íntegramente el criterio n-1, el que permite que el sistema de transmisión siga funcionando aunque una línea o componente importante de ella se haya caído. En la actualidad, la preocupación central de autoridades y expertos es asegurar que la transmisión no sea un obstáculo al desarrolo de iniciativas productivas, y que disponga de las holguras suficientes para absorber variaciones o fluctuaciones de la carga y la conexión de proyectos de ERNC $^{19}$.

15. Esto estaría desmintiendo la pretensión nacional de ser un país desarrollado o "jaguar", como se dijo hace un tiempo.

16. Presentación del ministro con motivo del lanzamiento del documento Aporte potencial de las Energías Renovables no Convencionales y de la Eficiencia Energética a la matriz eléctrica 2008-2025, elaborado por el Programa de Investigaciones en Energía del Instituto de Asuntos Públicos de la Universidad de Chile y el Núcleo Milenio de Electrónica Industrial y Mecatrónica y el Centro de Innovación en Energía de la Universidad Técnica Federico Santa María.

17. El Decreto Supremo de racionamiento preventivo $N^{\circ} 28$ de febrero de 2011 fue prorrogado en agosto del mismo año mediante el Decreto Supremo $N^{\circ} 58$, ulteriormente, se realizó una segunda prórroga para cubrir el año 2012.

18. El reportaje central de la revista Electricidad, № 153, de noviembre de 2012, se titula: "Sistema de transmisión eléctrica, en pos de la holgura y la robustez".

19. Una de las críticas al desarrollo de los sistemas de trasmisión en Chile deriva del hecho de que estos siguen a la expansión del parque generador y no se anticipa a esta, lo que afecta el transporte de carga entre zonas excedentarias y deficitarias, el desarrollo de las ERNC y la absorción de las sobrecargas. 


\section{Gráfico 4 \\ EVOLUCIÓN EN EL SIC DE LA POTENCIA INSTALADA, LA DEMANDA MÁXIMA Y LA POTENCIA FIRME20 (en MW)}

\section{Dem. Máxima vs Pot. Firme}

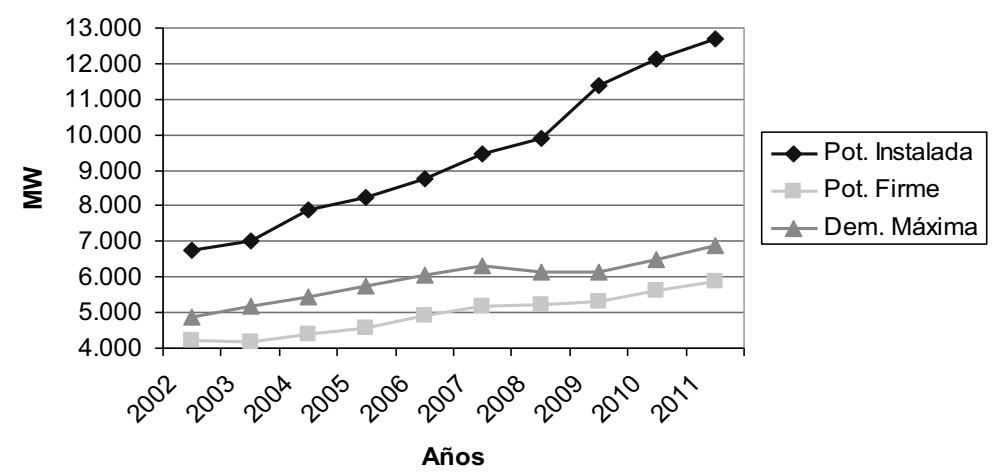

Fuente: Centro de Despacho Económico de Carga, CDEC-SIC, Estadísticas de operación 2002-2011.

\section{LA ENERGÍA Y LOS CONFLICTOS AMBIENTALES}

En Chile, parte importante de los conflictos ambientales se vinculan a la producción y uso de la energía. Hasta la fecha, la atención ciudadana ha estado concentrada en los contaminantes atmosféricos, ello se explica fundamentalmente por los impactos visuales y sobre la salud, resultante de la combustión de los derivados del petróleo, carbón, leña y gas natural ${ }^{21}$. Adicionalmente, en el último tiempo, la ciudadanía, mediante masivas movilizaciones, ha expresado su rechazo a un conjunto de macroproyectos de generación eléctrica, debido a que ellos atentaban contra las comunidades indígenas, agravaban los niveles de contaminación en zonas saturadas de un determinado contaminante o amenazaban la salud, a las actividades productivas o a las prioridades de desarrollo de las zonas en que se pretendía implantarlos. Ejemplo de lo señalado ha sido la resistencia y/o judicialización de proyectos tales como: Barrancones, Castilla, Campiche, Alto Maipo e HidroAysén. El escenario proyectado por el DICTUC de la Universidad Católica para el año 2010, muestra la importancia de las emisiones de PM10, PM2,5, CO, $\mathrm{NO}_{\mathrm{x}} \mathrm{y}$ $\mathrm{SO}_{\mathrm{x}}$ debidas al uso de combustibles fósiles y leña en los sectores industrial, residencial y del transporte, situación que se refleja en el cuadro siguiente.

20. En el caso de las centrales hidroeléctricas, la potencia firme depende de la variabilidad hidrológica y se determina con una probabilidad de excedencia de 95\% y, en el caso de las centrales térmicas, la potencia firme debe considerar factores de indisponibilidad programada y fortuita.

21. Mediciones recientes indican que Osorno, Temuco, Rancagua, Concepción, Valdivia y Santiago han superado significativamente la norma de material particulado fino (PM 2,5). Diario La Tercera, 16 de junio de 2013. 


\section{Cuadro 1}

INVENTARIO DE EMISIONES CONTAMINANTES ATMOSFÉRICAS EN LA RM, PROYECTADO 2010

\begin{tabular}{|c|c|c|c|c|c|c|c|}
\hline \multicolumn{8}{|c|}{$\begin{array}{l}\text { INVENTARIO DE EMISIONES ANUAL, ESCENARIO } 2010 \text { DISEṄO PPDA, REGION } \\
\text { METROPOLITANA } \\
\text { FUENTES ESTACIONARIAS Y MOVILES }\end{array}$} \\
\hline $\begin{array}{l}\text { Categoría de } \\
\text { Fuente }\end{array}$ & \begin{tabular}{|c|} 
PMl0 \\
ton/año
\end{tabular} & $\begin{array}{l}\text { PM2,5 } \\
\text { ton/año }\end{array}$ & $\begin{array}{c}\mathrm{CO} \\
\text { ton/año }\end{array}$ & $\begin{array}{c}\text { NOx } \\
\text { ton/año }\end{array}$ & $\begin{array}{c}\mathrm{COV} \\
\text { ton/año }\end{array}$ & $\begin{array}{c}\text { SOx } \\
\text { ton/año }\end{array}$ & $\begin{array}{c}\mathrm{NH3} \\
\text { ton/año }\end{array}$ \\
\hline Industria & $1.728,0$ & $1.358,3$ & $9.391,6$ & $12.596,1$ & $4.837,8$ & $5.378,4$ & 260,0 \\
\hline $\begin{array}{l}\text { Combustión de Leña } \\
\text { Residencial }\end{array}$ & $1.007,4$ & 979,0 & $12.105,7$ & 124,6 & $10.974,8$ & 17,3 & 104,3 \\
\hline Otras Residenciales & 92,0 & 85,7 & 388,8 & 1297,0 & $47.814,0$ & 199,6 & $4.534,4$ \\
\hline Comerciales & 0,0 & 0,0 & 0,0 & 0,0 & $7.057,9$ & 0,0 & 0,0 \\
\hline Quemas Agrícola & 166,7 & 158,7 & $1.446,6$ & 68,7 & 115,9 & 7,9 & 7,8 \\
\hline Otras Areales & 271,6 & 132,5 & $3.180,4$ & 85,5 & $18.397,3$ & 0,0 & $36.609,8$ \\
\hline Total Estacionarias & 3265,6 & 2714,3 & 26513,1 & 14171,8 & 89197,7 & 5603,2 & 41516,2 \\
\hline Buses Licitados & 82,3 & 69,7 & 873,8 & $2.967,4$ & 476,1 & 19,0 & 1,5 \\
\hline Otros Buses & 163,3 & 140,9 & 914,3 & $4.261,9$ & 453,9 & 6,8 & 2,0 \\
\hline Camiones & 877,3 & 768,3 & $4.158,9$ & $12.358,6$ & $2.702,9$ & 42,2 & 8,0 \\
\hline Veh Livianos Catalíticos* & 272,8 & 0,0 & $158.511,7$ & $14.262,6$ & $7.262,4$ & 89,9 & $1.441,7$ \\
\hline Veh Livianos No Catalit.* & 5,7 & 0,0 & $35.940,1$ & $7.108,3$ & $5.367,2$ & 2,5 & 0,9 \\
\hline Veh. Liv. Diesel Sin Sello & 54,7 & 48,4 & 392,0 & 734,8 & 48,6 & 1,2 & 0,2 \\
\hline Veh. Liv. Diesel Con Sello & 361,3 & 310,2 & $2.480,7$ & $3.578,8$ & 312,3 & 12,6 & 1,8 \\
\hline Veh Livianos Gas* & 1,7 & 0,0 & 775,6 & 45,8 & 44,0 & 0,0 & NE \\
\hline Motos* & 2,2 & 0,0 & $4.560,2$ & 29,0 & 823,5 & 0,5 & 0,4 \\
\hline Fuera de Ruta & 205,2 & 188,7 & $3.728,6$ & $1.490,3$ & 533,9 & 79,6 & 31,6 \\
\hline Total Móviles & $2.026,6$ & $1.526,1$ & $212 . .336,0$ & $46.837,4$ & $18.024,8$ & 254,3 & $1.488,0$ \\
\hline $\begin{array}{l}\text { TOTAL MOVILES Y } \\
\text { ESTACIONARIAS }\end{array}$ & $5.292,3$ & $4.240,4$ & $238.849,1$ & $61.009,2$ & $107.222,5$ & $5.857,4$ & $43.004,3$ \\
\hline
\end{tabular}

Fuente: Ingeniería DICTUC, Actualización del inventario de emisiones de contaminantes atmosféricos en la Región Metropolitana 2005. Escenario 2010; 31agosto 2007.

Del Cuadro 1 se desprende que el uso de la energía es responsable de más del 90\% de los contaminantes atmosféricos de la RM, salvo en el caso de los COVs o del $\mathrm{NH}_{3}$.

Si bien el cambio climático no ha constituido una preocupación central de la sociedad chilena ni de sus autoridades y, cuando ha estado presente en el debate público, este más bien ha tenido un carácter retórico y no se ha traducido en políticas públicas concretas destinadas a la mitigación de los gases de efecto invernadero (GEI). En el año 2008, CONAMA preparó el Plan de Acción Nacional de Cambio Climático 2008-2012, el que incluía un diagnóstico y las líneas prioritarias de acción, comprendiendo: adaptación a los impactos del cambio climático, mitigación de la emisión de GEI, creación y fomento de capacidades.

Este plan debió servir de hoja de ruta para los distintos actores públicos y privados involucrados en llevar adelante las políticas, programas y actividades vinculadas a mantener bajo control los parámetros que determinan el cambio climático y la velocidad del mismo. Desgraciadamente, el esfuerzo señalado no se expresó en medidas específicas, lo que no fue un obstáculo para que el país asumiese un compromiso de reducción de la emisión de los GEI al asociarse al Acuerdo de Copenhague el 29 de enero de 2010, donde presentó información para su inclusión en el Apéndice II del Acuerdo: 
"Chile will take nationally appropriate mitigation actions to achieve a $20 \%$ deviation below the "Business as Usual" emissions growth trajectory by 2020, as projected from year 2007. To accomplish this objective Chile will need a relevant level of international support. Energy efficiency, renewable energy, and Land Use and Land Use Change and Forestry measures will be the main focus of Chile's nationally appropriate mitigation actions"22.

Resulta difícil visualizar cómo se podrán cumplir estas metas, si se considera que recién se está realizando un estudio que define la línea de base para el año 2007, dentro de un programa que debería conducir a identificar las medidas de mitigación ${ }^{23}$. En parte importante, Chile ha asumido formalmente su responsabilidad frente al cambio climáti$\mathrm{CO}^{24}$, pero manteniendo sus reticencias a llevar a cabo una decidida política de reducción de las emisiones de GEI, esgrimiendo implícitamente el derecho al desarrollo y el que las emisiones de Chile son irrelevantes a nivel internacional.

En efecto, las emisiones de $\mathrm{CO}_{2 \text { eq }}$ no representan más del 0,2\% de las emisiones mundiales; sin embargo, estas se han más que duplicado en el período 1984-2006, las emisiones per cápita superan a la mayoría de las de los países de la región y, por último, de mantenerse los programas de instalación de centrales a carbón previstas para los próximos años, ellas aumentarán en forma significativa, haciendo aún más difícil el cumplimiento del compromiso adquirido al asociarse al Acuerdo de Copenhague. Esta visión podría modificarse como resultado de posibles presiones exógenas de los socios comerciales de Chile, los que tendrían la capacidad de forzar cambios en la actitud de las autoridades, así como en la de los sectores usuarios, especialmente en las actividades exportadoras, cuya competitividad podría verse afectada por la huella de carbono de sus productos.

El análisis detallado de los inventarios nacionales permite identificar a la producción y uso de la energía como la fuente responsable de un 75 a un $80 \%$ de las emisiones de GEI. El Gráfico 5 ilustra la evolución reciente de las emisiones de GEI.

Como fuera señalado previamente, los proyectos de generación eléctrica han sido objeto de rechazo y masivas movilizaciones de la ciudadanía, rechazo al que se han sumado especialistas e, incluso, un número relevante de parlamentarios. En parte importante, ello se origina en defectos de la legislación ambiental y del proceso de aprobación de los proyectos. En los aspectos más globales, el rechazo a los proyectos proviene de la falta de un canal institucional que posibilite una participación ciudadana informada y

22. Ministerio de Medio Ambiente, Segunda comunicación nacional de Chile ante la Convención Marco de las Naciones Unidas sobre Cambio Climático, Santiago, 2011, pág. 29.

23. MAPS Chile, resultante de la internalización de un proyecto originado en Sudáfrica, Mitigation Action Plan and Scenarios, durante los años 2005-2008. Actualmente, en América Latina, se realizan proyectos MAPS en Brasil, Chile, Colombia y Perú. Es decir, el país continúa realizando estudios en vez de llevar a cabo medidas identificadas en estudios anteriores.

24. En relación al compromiso de disminuir las emisiones de GEI en un 20\% al año 2020, la ministra de Medio Ambiente declaró en una entrevista a La Tercera, del 16 de junio de 2013, que Chile está decidido a cumplir con su compromiso, para lo cual desarrolla una serie de iniciativas. 
vinculante (por lo menos en la definición de los grandes ejes de la política energética ${ }^{25}$ ), la falta de una política explícita de Ordenamiento Territorial y su vinculación con el diseño e implementación de la política eléctrica, insuficiencias en lo que respecta a la consulta a los pueblos originarios en caso de proyectos que afectan su hábitat (Acuerdo 169 de la OIT), la transgresión de la preservación de las áreas silvestres protegidas y la institucionalidad definida para la aprobación ambiental de los proyectos.

\section{Gráfico 5}

EMISIONES, CAPTURA Y BALANCE DE GEI

(en $\mathrm{Gg} \mathrm{CO}_{2 \mathrm{eq}}$ )

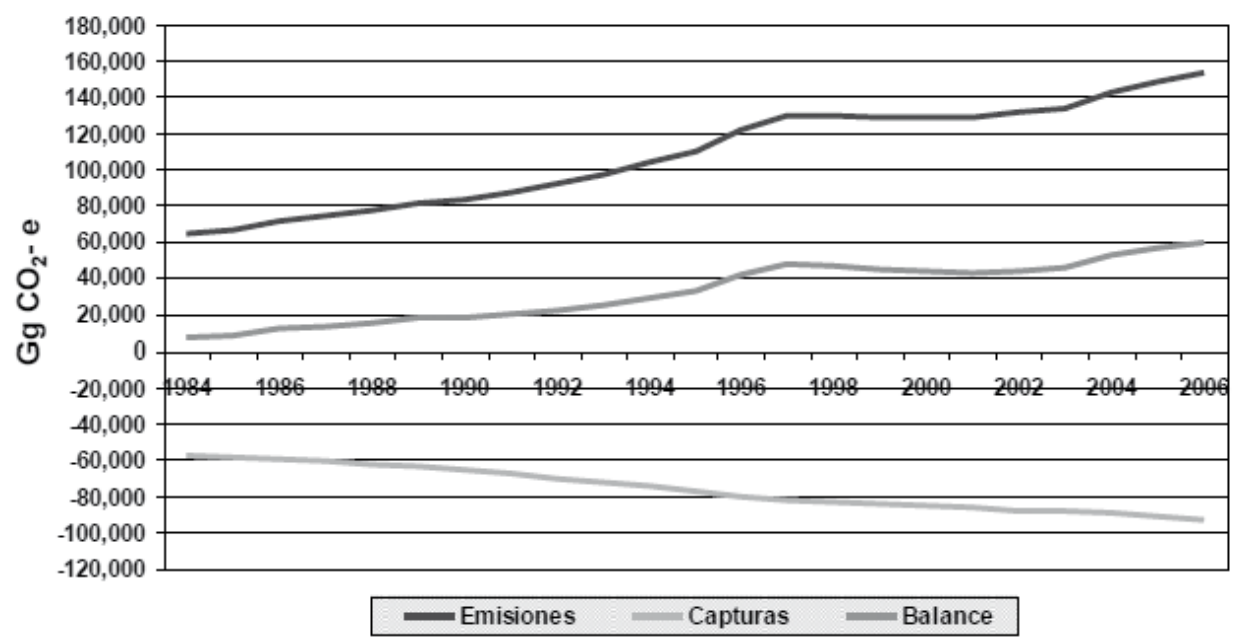

Fuente: Ferreiro, C., jefe del Departamento de Cambio Climático de CONAMA, presentación en el Mes de la Energía del Colegio de Ingenieros, 15 de junio de 2010.

En relación a este último punto, no es presentable que la empresa interesada defina la ubicación, diseño y operación de la central y que el Estado no tenga más opciones que aprobar o rechazar el proyecto (este no se puede cambiar); que los Estudios de Impacto Ambiental (EIA) no sean acumulativos, sino que por proyecto (lo que es particularmente grave cuando se trata de centrales que utilizan una misma cuenca); que la empresa promotora del proyecto contrate al consultor responsable de la elaboración de la línea base ${ }^{26}$; que la aprobación del proyecto quede en manos de los SEREMIs, funcionarios de

25. La oposición a entregarle a la ciudadanía el derecho a decidir las determinaciones que afectan su calidad de vida, actual y futura, se escuda en un argumento que ha sido largamente desmentido por la experiencia internacional: "las decisiones en torno a las grandes opciones del desarrollo energético son muy complejas y solo pueden ser abordadas por los especialistas".

26. Para obviar el conflicto de interés del consultor, parece razonable que la línea base sea ejecutada por el Estado. Incluso, se dan casos en que los fondos asignados a este aspecto fundamental del estudio de impacto ambiental son insuficientes y limitan la profundidad del estudio. A modo de ejemplo, por 
confianza política que responden normalmente a las órdenes de los intendentes o ministros respectivos, saltándose, en muchos casos, los informes técnicos de los distintos servicios responsables de evaluar los impactos del proyecto.

\section{CONCENTRACIÓN DEL SECTOR Y ALTOS PRECIOS DE LA ELECTRICIDAD}

Un aspecto particularmente crítico del funcionamiento del sector es la elevada concentración de la propiedad del mismo en pocas manos, contradiciendo lo que fue el paradigma de la "reforma" del sector, que establecía la competencia como uno de los pilares de la creación de un sistema eléctrico "eficiente y económico". A treinta años de la aplicación del modelo, no se logró la competencia ni el sistema alcanzó la racionalidad económica: las duplicaciones de inversiones, el uso de las tecnologías más caras e ineficientes y las elevadas tarifas que pagan los usuarios residenciales, industriales y mineros, permiten poner en duda las "bases fundacionales del sistema".

En el Sistema Interconectado Central (SIC) tres empresas (ENDESA, Colbún y Gener) concentran más del $85 \%$ de la generación del sistema ${ }^{27}$, la eventual materialización del proyecto HidroAysén tenderá a incrementar la concentración. En el caso del SING, E-CL 28 , AES Gener y Gas Atacama concentran del orden del 94\% ${ }^{29}$. Esta situación es atentatoria contra la sustentabilidad del país, ya que ella acarrea la concentración económica y, por ende, tiende a provocar un desequilibrio del poder político. En estas condiciones, es dudoso que se pueda legislar en función de los intereses de la mayoría si las reformas necesarias entran en colisión con los intereses de las empresas que manejan el dónde, el cómo y el cuándo de la inversión en infraestructura eléctrica. Estas empresas, a través de los contratos con clientes libres y las licitaciones para clientes regulados, tienen capturado del orden de un 90\% del mercado total hasta el año 2020, lo que deja un muy reducido margen para la entrada de nuevos actores.

Esta concentración es responsable en gran medida de los elevados precios que se pagan en el mercado eléctrico, sin que ello obligatoriamente suponga colusión, pero afecta el ritmo y tipo de inversión, factores que sí condicionan los precios que se pagan por la electricidad, a lo que se agrega la variación de los precios de los combustibles en el mercado mundial. De acuerdo a la Biblioteca del Congreso Nacional, los precios de la electricidad en Chile, tanto al nivel industrial como residencial, son respectivamente US\$ 43/MWh y US\$ 53/MWh más altos que el promedio de la OCDE (se consideran 34 países), y en relación a América Latina, los precios de Chile superan en US\$20 a 25/MWh a los países que presentan los precios más altos de la región, tanto para la

razones de costo, en proyectos hidroeléctricos, se podría sacrificar la evaluación del transporte de fondo por el análisis del transporte en suspensión, lo que impide modelar los sedimentos en el lecho del río.

27. CDEC-CIC, Estadísticas de operación 2002-2011.

28. Empresa del grupo International Power GDF Suez.

29. CDEC-SING, Anuario y Estadística de Operación 2011 y páginas web de las empresas. 
industria como para el sector residencial ${ }^{30}$. El Gráfico 6 ilustra la evolución de los precios de la electricidad en Chile para el período que se indica.

\section{Gráfico 6}

EVOLUCIÓN DE LOS PRECIOS DE NUDO DE LA ENERGÍA EN EL SIC Y EL SING, 1991-2010

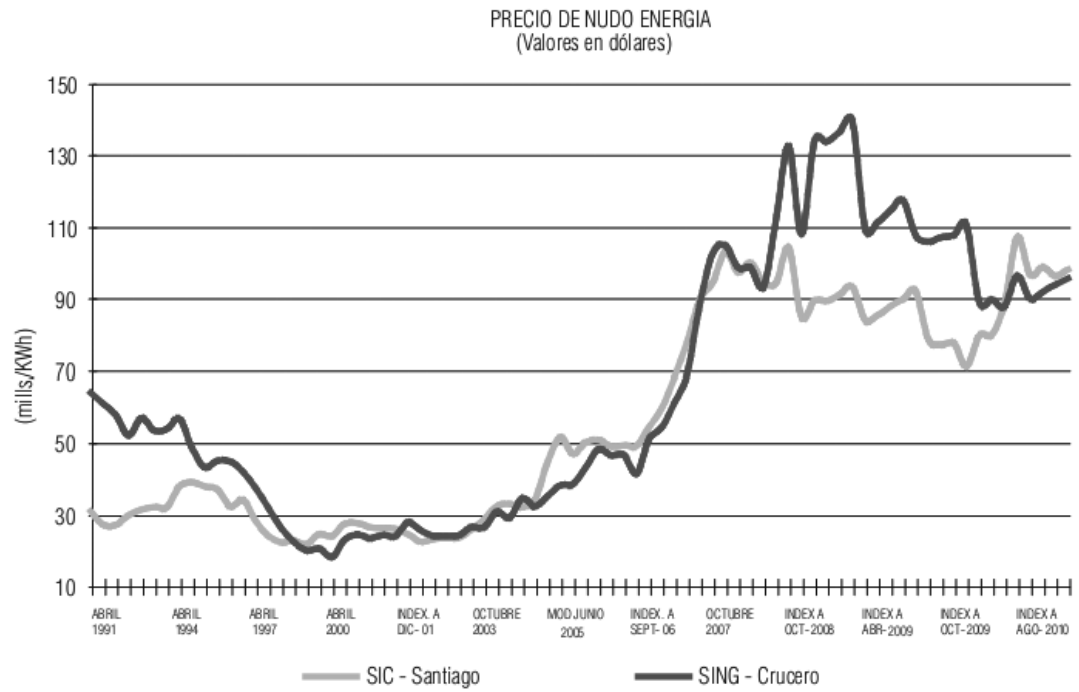

Fuente: Compendio Energético Chile 2011.

Nota: entre agosto de 2010 y diciembre de 2011, el precio de mercado subió en 11\%, según página web CNE.

Las autoridades y algunos expertos, reconociendo los altos precios de la electricidad, afirman periódicamente que estos se normalizarán en un par de años y que esta situación se debe a que el mercado está desadaptado, olvidando que tanto el alcanzar un mercado adaptado como el uso del esquema tarifario marginalista presuponen un mercado perfecto, lo que, como se ha visto, dista mucho de ser realidad.

El Gráfico 7 muestra las previsiones de los expertos respecto de los precios spot y los resultados efectivos de estas. Como lo señala el Ing. Juan Cembrano, las expectativas de menores precios han desalentado a los eventuales nuevos actores a invertir en condiciones que pueden ser riesgosas para ellos.

30. Biblioteca del Congreso Nacional, BCN Informe: Comparación de los precios de la electricidad en Chile y países de la OCDE y América Latina, 21 noviembre 2012. Elaborado en base a información de la International Energy Agency para la OCDE y de US Energy Information Administration para América Latina (información de América Latina corresponde a 2008). 


\section{Gráfico 7}

PRECIO SPOT DE LA ENERGÍA: ERRORES EN LAS PROYECCIONES HAN DESINCENTIVADO A LOS NUEVOS ACTORES, ERNC Y OTROS

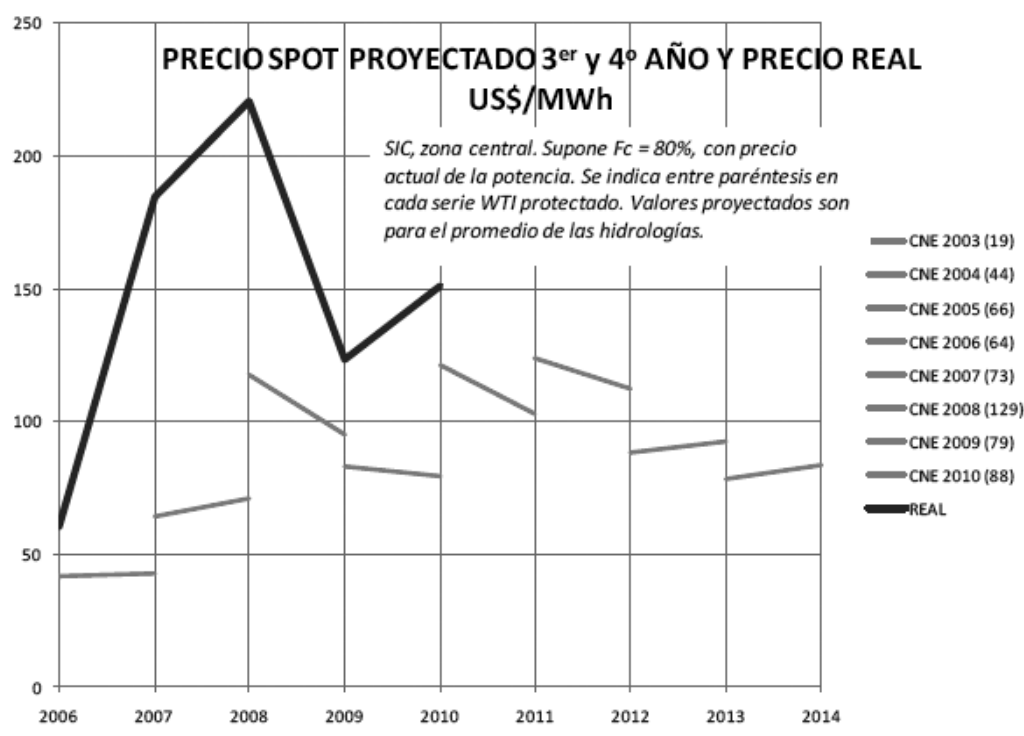

Fuente: Cembrano, J., director del CDEC-SIC, "Mercado Eléctrico Chileno: Problemas y soluciones en Generación", presentación a la Comisión Ciudadana Técnico Parlamentaria, agosto 2011.

Los precios spot están determinados por los costos marginales del sistema, los que han sido extraordinariamente altos, particularmente por la influencia del petróleo diesel en la generación eléctrica. Si bien el objetivo inicial de estos precios era valorizar los intercambios entre generadores deficitarios y excedentarios, actualmente ellos están determinando tanto el precio de las licitaciones para el abastecimiento de las distribuidoras como los contratos con clientes libres, donde existe una tendencia a cerrar contratos a precio spot más una comisión por administración, lo que implica que se han traspasado los riesgos del proveedor al cliente.

Por último, los altos niveles de precio de la energía tienen un claro impacto sobre la equidad social. De acuerdo a los resultados de la encuesta de presupuestos familiares del INE, en el año $2006^{31}$, el primer quintil gastaba casi un $11 \%$ de su presupuesto familiar en energía y el quinto quintil un 3,9\%. Es probable que la situación haya empeorado en estos años, ya que las alzas de precios de la energía muy probablemente han superado las mejoras de ingresos de las familias.

31. Encuesta que se realiza cada diez años. 


\section{PROPUESTA DE REFORMA DEL ESQUEMA REGULATORIO}

El insatisfactorio funcionamiento y la opacidad institucional del sistema eléctrico provocaron problemas económicos, sociales, ambientales y de seguridad y calidad del suministro, lo que impulsó la realización de cambios a la legislación que se había mantenido casi sin modificaciones desde su formulación en el año 1982.

Es así como en el año 2004 se introducen reformas a través de la llamada Ley Corta I (Ley $N^{\circ}$ 19.940), a fin de brindar mayor seguridad y calidad del suministro a precios razonables. Esta ley introdujo una regulación en el segmento de transmisión, redujo la banda de variación del precio de nudo respecto de los contratos con clientes libres, amplió la posibilidad de optar al mercado de clientes libres por parte de los regulados ${ }^{32}$, abrió el mercado eléctrico a las pequeñas centrales de ERNC, liberó del pago de peajes en la transmisión troncal a centrales de menos de 9MW y parcialmente en el caso de centrales de 9 a 20 MW, y creó un Panel de Expertos para resolver las controversias en el sector y de las empresas con las autoridades.

En el año 2005, se dicta la Ley Corta II (Ley No 20.018) en el contexto de las restricciones de abastecimiento del gas natural desde Argentina, lo que creaba incertidumbres al nivel de los contratos y posibles ingresos. Esta ley, fundamentalmente, incorporó las licitaciones de contratos a largo plazo por parte de las distribuidoras; para hacer más atractivas las licitaciones, amplió la banda de ajuste de los precios regulados respecto de los precios de los contratos con clientes libres, incluyó incentivos al ahorro en períodos de estrechez o al aumento en el consumo, en caso de superávit de oferta; y eliminó las restricciones de gas natural de Argentina como causal de fuerza mayor.

En el año 2008, se promulga la llamada Ley de Energías Renovables No Convencionales (Ley $\mathrm{N}^{\circ}$ 20.257). En ella, se liberan de los limites de potencia a las ERNC ${ }^{33}$, salvo la minihidráulica, cuyo límite se fija en $40 \mathrm{MW}$, y se determina que toda empresa que realice retiros de energía desde una red con capacidad superior a 200 MW, para comercializarla con distribuidoras o clientes finales, deberá acreditar que un equivalente al 5\% entre el año 2010 y 2014 corresponde a ERNC, valor que irá aumentando anualmente en $0,5 \%$ hasta llegar a $10 \%$ en el año 2024. En caso de que no se logren los montos que señala la ley, la empresa deberá pagar una multa de 0,4 UTM/MWh por ERNC no abastecido y, en caso de reincidencia, la multa ascenderá a 0,6UTM/MWh. El porcentaje se aplica a todos los contratos que se suscriban a partir del 31 de agosto de 2007 y mediante medios de producción cuya instalación se haya realizado después del 1 de enero del $2007^{34}$.

32. Esta medida no fue muy exitosa, ya que los altos precios de los contratos incitaban a los clientes a mantener su condición de regulados.

33. Definido en $20 \mathrm{MW}$ para los efectos de la eliminación total o parcial del pago de peajes en la transmisión, como se señala en el párrafo correspondiente a la Ley Corta I.

34. Esta restricción limitó significativamente las ventas de energías renovables, ya que solo se aplica a un porcentaje limitado de los contratos vigentes. 
Las modificaciones realizadas hacen honor a su nombre de "Leyes Cortas", vale decir, no constituyen una reforma mayor del sistema y dejan en pie parte importante de las causales que determinan las deficiencias descritas previamente. Las movilizaciones de la sociedad civil contra HidroAysén y otros megaproyectos indujeron al presidente Piñera a crear la Comisión Asesora para el Desarrollo Eléctrico (CADE), para generar una respuesta a los problemas que evidenciaba el funcionamiento y desarrollo eléctrico. Los movimientos ciudadanos no le reconocieron a CADE la independencia suficiente para realizar cambios mayores a la legislación eléctrica vigente y, en respuesta a esta determinación presidencial, se organizó la Comisión Ciudadana Técnico Parlamentaria (CCTP), con el objetivo de realizar un diagnóstico integral de la situación y proponer las reformas necesarias para avanzar hacia la elaboración de un marco normativo que responda a las necesidades de la sociedad en su conjunto.

Las propuestas bosquejadas en este artículo decantan el resultado de los análisis, realizados por un conjunto de especialistas, del funcionamiento del sistema eléctrico desde los años 80 , y que se enriquece con los debates y conclusiones de la CCTP ${ }^{35}$, propuestas que el autor comparte plenamente debido a que formó parte activa de la Comisión. En caso de requerirse mayores antecedentes, puede consultarse el documento de la CCTP como referencia. Las medidas que se estiman necesarias apuntan a una profunda reforma del mercado eléctrico, a transformar la eficiencia energética en una opción estratégica de la política energética, a masificar la incorporación de las ERNC en la matriz eléctrica del país, a la incorporación de los costos externos en la generación eléctrica y a la generación de canales de participación ciudadana informada y vinculante.

Un mercado eléctrico como el chileno: vulnerable, concentrado, carbonizado, sucio, inequitativo y $\mathrm{caro}^{36}$, requiere cambios en ámbitos tales como:

- Rol del Estado: Como se ha podido apreciar, el concepto de Estado subsidiario ha sido confundido con el de un Estado que ha renunciado a ejercer un liderazgo en la conducción del sector, incluso en momentos de crisis, donde la inversión del sector privado no aparecía para resolverlas. El Estado tampoco intervenía, con lo que el consumidor quedaba y queda expuesto a sufrir un desabastecimiento pronunciado o un abastecimiento de mala calidad. Se estima necesario que en Chile, como en muchos países, el Estado asuma la definición de la planificación estratégica: a) abordando la diversificación de la matriz, b) la optimización de los recursos energéticos, c) la conciliación entre el desarrollo nacional y el abastecimiento energético, d) la planificación del desarrollo y ordenamiento territorial, incluyendo en ella, entre otros aspectos, las tecnologías de generación y el reforzamiento de la transmisión.

35. Comisión Ciudadana Técnico Parlamentaria, Chile necesita una gran reforma energética, Santiago, octubre 2011, 136 págs.

36. Se entiende por "sucio" las significativas emisiones de contaminantes atmosféricos (i.e. PM10, PM2,5, $\mathrm{SO}_{2}, \mathrm{CO}$ ), y por "carbonizado" las elevadas emisiones de GEI. 
- Desconcentración del mercado: El esquema regulatorio vigente ha sido incapaz de impedir la elevada concentración del sector, lo que impone la necesidad de asumir políticas específicas que apunten a un aumento de los actores. Al respecto, conviene señalar que a comienzos de los 90 se planteó que, en un sistema pequeño como el chileno, la desintegración vertical no aparecía como una buena alternativa y que la competencia sería muy difícil de alcanzar ${ }^{37}$. Brasil ha definido marcos regulatorios que prohíben a las empresas ser propietarias de más del 20\% de la capacidad instalada nacional, ni más de un 30\% de la capacidad de cada sistema interconectado. El gráfico $N^{\circ} 8$ muestra el resultado de los esfuerzos de desconcentración en Inglaterra y Gales, el que fue logrado forzando la desinversión de las tres empresas que concentraban el mercado.

\section{Gráfico 8}

RESULTADOS DE LA DESCONCENTRACIÓN DE LA PROPIEDAD DEL SISTEMA ELÉCTRICO INGLÉS

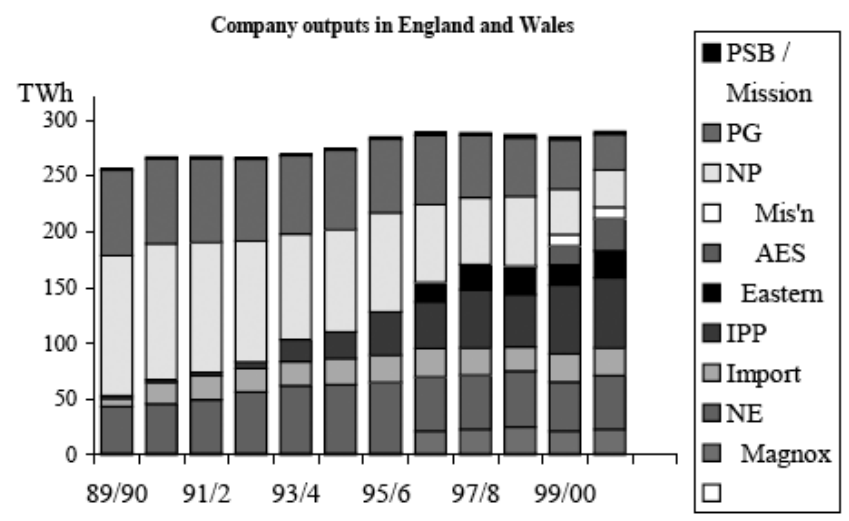

Fuente: Newbery, D., Regulating electricity to ensure efficient competition, Department of Applied Economics, Cambridge, UK, 20 October 2001.

- Modificación de las licitaciones para el abastecimiento de las distribuidoras: El esquema de las licitaciones vigentes no ha hecho más que concentrar el mercado eléctrico chileno, contradiciendo a quienes lo concibieron e implementaron, argumentando que este constituía un mecanismo adecuado para la entrada de nuevos actores, específicamente a los generadores en base a ERNC, lo que no ocurrió. Una de las principales trabas consiste en que el lapso de tiempo entre la licitación y el cumplimiento del eventual contrato es solo de tres años, lo que favorece a las generadoras de gran tamaño, que disponen de distintas tecnologías

37. PRIEN, Reestructuración energética y desarrollo sustentable: El caso del sector eléctrico chileno, División de Recursos Naturales y Energía de la Comisión Económica para América Latina y el Caribe (CEPAL), LC/R 1494/Rev.1, 13 abril 1995. 
y cuyas centrales están distribuidas en diferentes zonas geográficas ${ }^{38}$, ya que un actor nuevo en un período tan breve no alcanza a cumplir con todas las exigencias y corre los riesgos de las fluctuaciones de precios. En estas condiciones, se recomienda alargar el plazo entre licitación y cumplimiento del contrato, y que se realicen licitaciones separadas para energías convencionales y ERNC, asegurando el cumplimiento de las cuotas definidas por la Ley $\mathrm{N}^{\circ} 20.257$ o la ley que reemplace a la actual ${ }^{39}$. Existe, adicionalmente, un debate acerca del alcance de las licitaciones: separadas por tecnologías de ERNC o sin distinguir tecnologías ${ }^{40}$.

- Reformulación del sistema marginalista: La distorsión del esquema marginalista ha dado origen a precios de la electricidad extraordinariamente elevados. Dada la falta de competitividad, el sistema favorece la posibilidad de ganar más sin invertir, ya que con ello es más probable que la punta de la demanda sea abastecida mediante instalaciones ineficientes y, además, sucias. La fuerte inversión reciente en grupos diesel favorece que los costos marginales sean elevados y los precios sigan las variaciones de estos ${ }^{41}$. Es posible pensar en licitaciones separadas para abastecer la demanda de punta.

- Modificar la institucionalidad de los Centros de Despacho Económico de Carga (CDEC): Dado que sus decisiones o falta de decisiones afectan el funcionamiento del mercado eléctrico, parece fundamental eliminar la dependencia administrativa y económica respecto de las grandes empresas eléctricas, reemplazándolas por centros de operación independiente para cada sistema, responsables del cumplimiento de las actuales funciones o que, incluso, cubran algunas o todas las realizadas por el Panel de Expertos, como existe, por ejemplo, en California ${ }^{42}$.

- Garantías de información pública sobre los costos de los distintos segmentos del sistema: Esto debe ir encaminado a generar espacios formales y efectivos de participación en los procesos tarifarios, fundamentalmente en lo que se refiere a los modelos y formas utilizadas por las autoridades y empresas para fijar las tarifas.

38. Lo que le concede ventajas comparativas frente a las alteraciones de las condiciones meteorológicas y a las variaciones del costo marginal.

39. Ver más adelante el estado del eventual cambio de la ley.

40. La primera opción tiene por objeto diversificar las tecnologías ERNC. Dada la complejidad de asignar cuotas a cada tecnología, una alternativa simple sería realizar licitaciones por bloques en las barras principales del sistema, lo que conduciría a que en cada barra la distribución se defina por las competitividades relativas, asegurando en algunas zonas la preeminencia solar, en otras la geotérmica, y en otras la minihídrica, por ejemplo.

41. Incluso hubo licitaciones indexadas al costo marginal o, como se señalara, hay contratos en que el proveedor traspasa directamente el precio spot al cliente, agregando una comisión por el servicio.

42. Ver la California Independient System Operation Corporation. Se trata de una corporación sin fines de lucro, responsable del buen funcionamiento de los distintos componentes del sistema. 
En cuanto a las opciones tecnológicas para asegurar un abastecimiento sustentable de los requerimientos energéticos, se debe reiterar que no existe una respuesta única y que una diversificación responsable incluirá distintas fuentes, en un proceso que tienda en el mediano plazo a una matriz eléctrica más limpia, con mínimos impactos socioambientales y menores costos. Ello no excluye la existencia de centrales a carbón bajo el precepto de que las tecnologías correspondan a lo que se define como carbón limpio (i.e. ciclo súpercritico, lecho fluidizado y/o gasificación de carbón integrada a ciclo combinado (IGCC) y/o captura y almacenaje de carbono (CCS), en la medida en que las opciones descarbonizadas asuman crecientemente un rol dominante en la matriz.

El Sr. Tanaka, director ejecutivo de la Agencia Internacional de la Energía (AIE), presentó en Chile, el 23 de octubre del 2009, la estrategia de la AIE (IEA, en inglés) para reducir las emisiones de GEI y estabilizar su concentración en la atmósfera a 450 ppm, lo que implicaría, al año 2100, un alza de no más de 2 C respecto de la temperatura media de fines del siglo XX. Dicha estrategia supone que, al año 2020, un 65\% del esfuerzo de mitigación correspondería a la eficiencia energética (EE) y un 18\% a las ERNC, y al año 2030 se reduce la importancia de la EE a 57\% y aumentan las ERNC a 20\%. Incluidos los biocombustibles, las tres opciones tecnológicas aportarían a la meta de mitigación algo más de un $80 \%$, tanto para el 2020 como para el $2030^{43}$. Esta situación, unida a un vasto conjunto de beneficios, explica la importancia que se asigna a la EE y las ERNC en esta propuesta de política energética.

\section{LA EFICIENCIA ENERGÉTICA (EE), UNA OPCIÓN ESTRATÉGICA PARA LA POLÍTICA ENERGÉTICA NACIONAL}

La EE es una fuente de energía renovable, no contaminante, segura y de mínimo costo. En los párrafos siguientes no se hacen distinciones entre la electricidad y los usos de los combustibles, en lo que respecta a la política de EE, ya que las medidas y programas que derivan de ella son genéricos y, en muchos casos, estas fuentes son intercambiables.

La EE constituye un componente central de la política energética debido a que ella contribuye a: a) la seguridad del abastecimiento, b) la sustentabilidad energética, c) la reducción de la dependencia externa, d) la equidad, y e) la democracia, ya que incorpora millones de agentes que aportan al abastecimiento de los requerimientos de calefacción, refrigeración, fuerza motriz, transporte, procesos electroquímicos, entre otros. La EE apunta a proveer los mismos o mejores servicios utilizando menos energía, sin sacrificar el confort ni la actividad productiva o de servicios ${ }^{44}$.

43. Al año 2030, la captura y almacenamiento de carbono (CCS) representaría un $10 \%$ del esfuerzo de mitigación, y la energía nuclear reduciría su importancia relativa de $13 \%$ a 10\%, entre el 2020 y 2030, como opción para mitigar la emisión de GEI.

44. Este concepto desmiente la argumentación: "Chile es un país pobre; luego, debe consumir más energía y no menos energía”, esta confusión se origina en campañas gubernamentales que confunden EE con ahorro, este último concebido como sacrificio del confort. 
A pesar de los beneficios evidentes que la EE representa para la sociedad, Chile durante más de treinta años la ignoró, afirmando que el mercado arregla todo y que si la EE es buena para la gente, esta la adoptará, y si no lo es, el Estado no debe intervenir. Ello demostró la ignorancia sistemática de las autoridades, que no entendían que existían barreras que impedían que el mercado operara, situación que se repetía en los países desarrollados, los que, concientes de ello, generaron decididas políticas de EE para superar las barreras, y que muchos de ellos crearon leyes de EE, como es el caso de Japón, que estableció normativas estrictas y detalladas en el caso de las principales empresas consumidoras de energía, exigentes estándares para los principales equipos usuarios de energía e incentivos específicos para los distintos tipos de usuarios.

La situación descrita cambió en el año 2005 como resultado de la crisis de abastecimiento de gas natural desde Argentina, generándose un conjunto de iniciativas lideradas por el Programa País de Eficiencia Energética que apuntaron fundamentalmente a ampliar el conocimiento de cómo se usa la energía en Chile, a diseñar la institucionalidad requerida y a generar un Plan Nacional de Acción de Eficiencia Energética. Desgraciadamente, dicha institucionalidad no alcanzó a consolidarse y, con el cambio de gobierno, en el año 2010 se produce un segundo punto de inflexión en el tema, que hace temer que se pierda parte de los esfuerzos realizados.

A continuación, se detallan brevemente los componentes de una política de EE para Chile, la que apunta al desarrollo o reforzamiento de la institucionalidad requerida, y de un conjunto de medidas y programas a implementar en el corto plazo.

\section{INSTITUCIONALIDAD PROPUESTA}

- Ley marco de EE: Ella es indispensable para transformar la EE en una política de Estado y no en una política de gobierno, como ha sido hasta la fecha. Esta última condición la pone a merced de las prioridades que defina cada ministro, lo que ha sido especialmente grave a partir del año 2010, en el cual, en un período de tres años, han existido cinco ministros y un sexto que actuó de facto. Evidentemente, la existencia de la ley es una condición necesaria, pero por sí sola su existencia no asegura que se cumplan los objetivos que se pretenden lograr con ella, si no se cuenta con una voluntad política al más alto nivel, que impulse las iniciativas que surgen de la ley y que, muchas veces, están alojadas en distintos ministerios. Ella deberá ser suficientemente específica y definir, al menos: alcance, sectores objetos de la ley, roles y responsabilidades de los principales actores, financiamiento e institucionalidad. Un acápite especial de ella deberá establecer el tratamiento que se dará a las empresas que concentran el consumo de energía en el país; el reglamento de la misma será concreto tanto en las obligaciones de dichas empresas como en los lineamientos, programas y planes para las principales áreas de la actividad socioeconómica y los incentivos, subsidios y estándares que fomenten un consumo más eficiente de la energía. 
- Agencia Chilena de Eficiencia Energética (AChEE): La actual Agencia fue creada con carácter de agencia pública-privada, sin embargo, las distorsiones e influencias paralizantes de intereses contrapuestos sugiere que ella adquiera un estatuto legal de institución pública, asegurándole una autonomía operativa y financiera, para que no se vea sometida a los vaivenes de la coyuntura económica, política o de otro orden, como ha ocurrido con su financiamiento ${ }^{45}$ e, incluso, con su rol específico. El Ministerio de Energía será responsable de la definición de las políticas y los principales lineamientos de esta, y de asegurar a la Agencia un sólido mandato legislativo que le permita desarrollar, implementar o hacer implementar, monitorear y evaluar programas de los sectores usuarios prioritarios, tener información oportuna y adecuada proveniente de distintos servicios públicos y de empresas privadas, y coordinar esfuerzos tanto con el sector público como con el privado. El director de la Agencia deberá ser elegido mediante el sistema de la Alta Dirección Pública y responder del cumplimiento de las metas y del uso del presupuesto ante el Parlamento.

- Adoptar desde ya el Plan Nacional de Acción de Eficiencia Energética (PNAEE): Este Plan fue desarrollado durante el gobierno anterior y aprobado el año 2010. A pesar de ello, las autoridades no lo adoptaron oficialmente hasta el 6 de mayo del 2013, cuando se lanza un documento que incluye básicamente una descripción de las áreas de uso de la energía, las metas globales por sector y una breve descripción de las líneas de acción identificadas para cada sector, sin especificar claramente cómo se lograrían esas metas, lo que lo distingue claramente del documento que le dio origen ${ }^{46}$ y que tenía como objetivo servir como la hoja de ruta de los actores públicos y privados involucrados en programas de EE. A diferencia de la opción tradicional de ejecutar programas aislados, este último apuntaba a coordinar a las instituciones involucradas, definir roles y responsabilidades, detallaba programas y actividades asociadas a las distintas líneas de acción, los presupuestos requeridos, cronogramas y beneficios esperados; adicionalmente, contemplaba incentivos, subsidios, regulaciones, normativas y esquemas de financiamiento.

- Proyecto de ley de desacople de los ingresos por ventas de las distribuidoras: Este proyecto estaba listo para ser enviado al Parlamento a fines del 2009 y fue archivado sin que se vuelva a hablar de él. Su objetivo era romper el círculo

45. El presupuesto de la Nación asignó a la AChEE \$ 30.000 millones para el año 2010 (el que incluía el reacondicionamiento térmico de 750.000 vivienda para el decenio). Dichos recursos fueron reasignados a las tareas de reconstrucción. Al año 2012, se eliminó el Programa de Reacondicionamiento Térmico y el presupuesto se redujo a unos $\$ 3.400$ millones. Esta situación sugiere que el financiamiento de la Agencia se independice del presupuesto general y del presupuesto del Ministerio de Energía. Se ha planteado, por ejemplo, que el financiamiento provenga de un pequeño cargo en las tarifas eléctricas y en el precio de venta de los combustibles, como ocurre en California o Uruguay, por ejemplo.

46. PRIEN, Estudio de bases para la Elaboración de un Plan de Acción Nacional de Eficiencia Energética 20102020, 2010. 
vicioso ventas-utilidad, paradigma del sector, generando un mecanismo tarifario que incentivara a las distribuidoras a realizar inversiones y esfuerzos destinados a mejorar la eficiencia con que sus clientes utilizan la energía, asegurando una remuneración adecuada que compensara la pérdida de ventas, de manera que la EE no fuera vista como una amenaza para ellas, sino como un negocio igualmente lucrativo que sus actividades convencionales.

Conjuntamente con los cambios institucionales se sugiere llevar a cabo, reimpulsar programas o intensificar los esfuerzos que se realizan en el ámbito de la $\mathrm{EE}$, algunas de estas medidas o programas serían los siguientes:

- Reimpulsar el programa de etiquetado, asociado a la aplicación de estándares mínimos: Lo que supone agregar a lo ya realizado los refrigeradores comerciales, sistemas de climatización, los motores y transformadores eléctricos, lavadoras, etc.

- Normativa específica para las empresas energo-intensivas: Establecer metas de reducción de los consumos en el caso de las empresas que concentran un porcentaje elevado del consumo nacional de energía ${ }^{47}$.

- Reforzar o instalar instancias certificadoras y de fiscalización: No se obtendrán resultados relevantes con solo establecer normativas o etiquetado, si el país no está en condiciones de certificar lo especificado por los proveedores o verificar el cumplimiento de las normativas.

- Reforzar y masificar los programas de capacitación: Estos programas deberán orientarse al uso, diseño, construcción e instalación de edificaciones y equipos usuarios de energía, a todos los niveles de formación desde ingenieros hasta operarios.

- Imponer el empleo de la metodología del costo del ciclo de vida: Se deberá establecer la obligatoriedad de utilizar en las construcciones públicas que licita el Ministerio de Obras Públicas el cálculo del costo del ciclo de vida (capital, operación y mantenimiento, tanto en los edificios como de los principales equipos usuarios de energía).

- Relanzar el programa de reacondicionamiento térmico de viviendas existentes: Este programa fue aprobado por el Ministerio de Vivienda y Urbanismo y se inició a una escala piloto con el objeto de ir gradualmente, y en un período acotado de tiempo, cubriendo un porcentaje significativo de las viviendas de los sectores de bajos ingresos, construidas con deficientes estándares de calidad térmica.

47. En el caso chileno, corresponde básicamente a la gran minería del cobre y las principales industrias manufactureras (cemento, siderurgia, celulosa, petroquímica, pesca, etc.). 


\section{FOMENTO DE LAS ENERGÍAS RENOVABLES NO CONVENCIONALES (ERNC)}

Como fuera señalado, en el año 2008 se dictó una ley destinada a fomentar las ERNC en el país. Si bien ello permitió dar concreción a un debate que se había instalado en el país, las metas definidas por la ley parecieron excesivamente conservadoras a diferentes sectores de la sociedad. Los problemas que presenta el sistema eléctrico chileno llevaron a estos mismos sectores, y a miembros del Senado primero y de la Cámara de Diputados después, a presentar una moción que cambiaba dichas metas y fijaba un $20 \%$ de ERNC al año 2020, lo que se dio en llamar la ley 20/2048. Conviene señalar que, siendo candidato, el presidente Piñera incorporó la meta del 20\% al 2020 en su programa de gobierno y, posteriormente, en el mensaje al país del 21 de mayo de 2010.

A fines del 2011, la Comisión Asesora para el Desarrollo Eléctrico (CADE) propuso aumentar del 10\%, que incluye la ley vigente, a 15\% la participación de las ERNC al 2024. Sin embargo, ni los anuncios previos del presidente ni la propuesta de la Comisión nombrada por él, están presentes hoy en la política gubernamental. Incluso, la cota del $5 \%$ no ha podido alcanzarse al estar sujeta a la cláusula de que ella se aplica para los contratos firmados con posterioridad a agosto del 2007.

Los opositores a subir la participación de las ERNC centran sus argumentos en los aspectos siguientes: la estructura de la matriz eléctrica chilena es similar a la que existe en el mundo, es muy difícil desarrollar en el corto plazo los proyectos necesarios para alcanzar la meta, las ERNC son mucho más caras que las energías convencionales y, por último, las energías renovables, básicamente eólica y solar, son intermitentes e imprevisibles. A continuación, se comentan brevemente estas afirmaciones:

- La estructura del parque generador chileno es similar a la media mundial: Este argumento, que pretende cuestionar el que se busque reducir la importancia relativa de las centrales a carbón, no tiene en cuenta cuál es la tendencia del mercado. El Gráfico 9 permite visualizar dicha tendencia.

La tendencia que muestra el Gráfico 9 no se ha modificado, es así como en el año 2011. En el mundo se invirtió 17\% más que en el 2010 (US\$ 257.000 millones), lo que es digno de destacar dada la crisis económica internacional. Excluidas las grandes centrales hidroeléctricas, las ERNC representaron un 44\% de la nueva capacidad. En ese mismo año, en Europa, un 70\% de la nueva capacidad correspondió a ERNC (32.043 MW, de un total de 44.939 MW), y en Estados Unidos, en el año 2012, un 49\% de la nueva capacidad correspondió a ERNC (12.956 MW), lo que representa un 51\% más que lo instalado en 2011.

48. La iniciativa parlamentaria fue aprobada por el Senado y por la Comisión de Minería y Energía de la Cámara de Diputados, y se está a la espera de las indicaciones del Ejecutivo, quién ha mostrado su escepticismo con esta iniciativa, al considerarla poco viable. Sin embargo, como resultado de las negociaciones entre el Parlamento y el Ejecutivo se estaría acordando aceptar la meta de 20\% para las ERNC al 2025, a cambio de la aprobación de las leyes de concesiones y de servidumbre impulsadas por el gobierno. 


\section{Gráfico 9}

TENDENCIA MUNDIAL DE LA INVERSIÓN EN ERNC

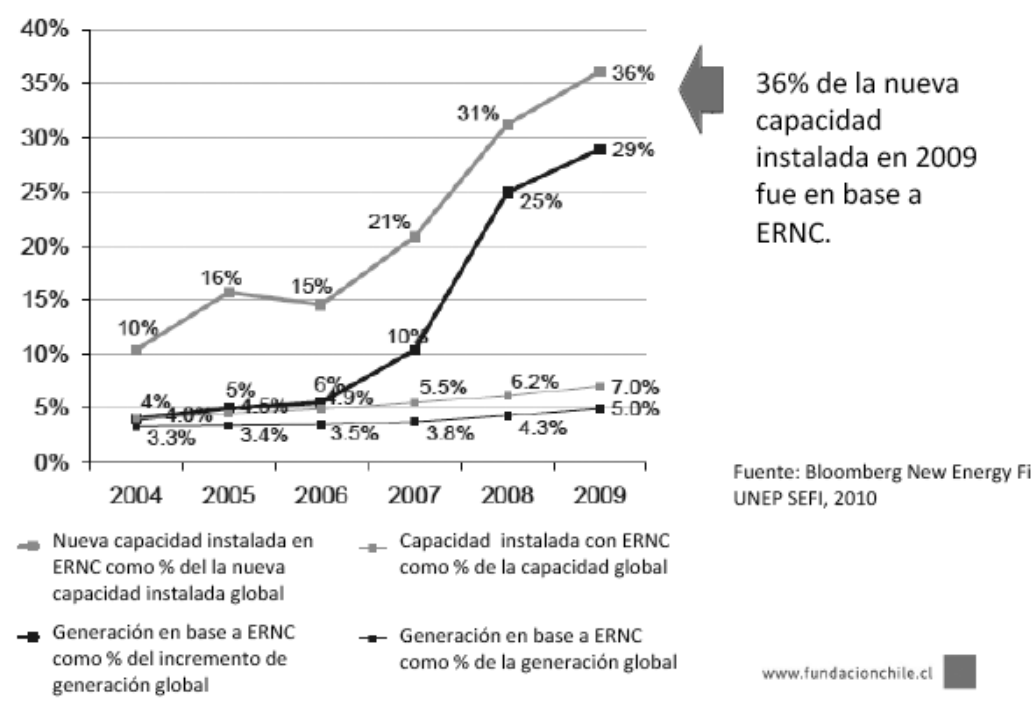

Fuente: Angulo, M., Fundación Chile, presentación en ELECGAS 2011, en base a UNEP SEFI y Bloomberg New Energy, Julio 2010.

\section{- Es muy difícil en Chile generar los proyectos de ERNC para cumplir con} la meta: Al respecto parece razonable hablar de $20 \%$ al año 2025, dado que el desarrollo de las ERNC es un proceso y este no se ha iniciado desde el punto de vista de los cambios normativos necesarios. Habida consideración del cambio de fecha, existen antecedentes que desmentirían el argumento de los sectores que buscan mantener a las ERNC como una opción marginal ${ }^{49}$. El Cuadro 2 resume la situación actual de los proyectos de ERNC.

\section{Cuadro 2}

PROYECTOS DE ERNC EN CHILE, CONSTRUIDOS, EN CONSTRUCCIÓN Y EN EL SISTEMA DE EVALUACIÓN DE IMPACTO AMBIENTAL

(en MW)

\begin{tabular}{|c|c|c|c|c|}
\hline & & & \multicolumn{2}{|c|}{ SEIA } \\
\hline Estado & $\begin{array}{l}\text { Operación } \\
\text { MW }\end{array}$ & $\begin{array}{c}\text { Construcción } \\
\text { MW }\end{array}$ & $\begin{array}{c}\text { RCA aprobada } \\
\text { sin construir }(\mathrm{MW})\end{array}$ & $\begin{array}{c}\text { En calificación } \\
(\mathrm{MW})\end{array}$ \\
\hline Minihidro & 294 & 89 & 248 & 114 \\
\hline Eólica & 205 & 248 & 3981 & 1350 \\
\hline Biomasa & 394 & 58 & 86 & 0 \\
\hline Solar & 3,6 & 3,3 & 3107 & 1061 \\
\hline Geotermia & 0 & 0 & 50 & 70 \\
\hline Total & 896 & 398 & 7473 & 2594 \\
\hline
\end{tabular}

Fuente: Centro de Energías Renovables, CORFO, Reporte CER, febrero 2013.

49. A pesar de que la exigencia hasta el año 2014 es de un 5\%, en abril de 2013, las ERNC entregaron un $7 \%$ de la energía del SIC. 
Los análisis desarrollados por la CCTP indicarían un crecimiento de la demanda de 60.000 GWh para el año 2025 respecto del año 2010, lo que implicaría que el parque generador ERNC debiera abastecer entre 20.000 y $22.000 \mathrm{GWh}$ ese año ${ }^{50}$. El resto de la nueva demanda, de acuerdo a la CCTP, sería abastecida con las centrales a carbón en construcción (9.700 GWh), la eficiencia energética (15.000 GWh) y la hidroelectricidad mediana y mayor, instalada en la zona centro-sur (15.000 GWh). En el punto siguiente, se presenta el portafolio de proyectos en cartera de ERNC y los factores de planta y precios considerados.

- Las ERNC son mucho más caras que las fuentes convencionales de energía: Por lo menos al nivel de Chile, este argumento podría cuestionarse si se consideran los precios que están pagando los usuarios en las licitaciones. El año 2005, se introduce el esquema de licitaciones de contratos de largo plazo para abastecimiento de las distribuidoras. Con ello se pretendía no solo incentivar la oferta para asegurar el abastecimiento futuro, sino que además dar certeza a las partes respecto de los precios ${ }^{51} \mathrm{y}$, por ende, de las rentabilidades esperables para las nuevas inversiones y las existentes. El resultado no ha sido tan exitoso porque, en las licitaciones de octubre 2007 y marzo 2008, un $61 \%$ y un $80 \%$ de la energía total licitada no fue adjudicada ${ }^{52}$. En 2012, la licitación que impulsó la Compañía General de Electricidad (CGE) se declaró desierta pese a establecer un precio techo de US\$ 129/MWh. El Gráfico 10 ilustra la evolución de los precios de las licitaciones para el abastecimiento de clientes regulados.

\section{Gráfico 10}

RESULTADO DE LAS LICITACIONES PARA ABASTECIMIENTO DE LAS DISTRIBUIDORAS EN CHILE

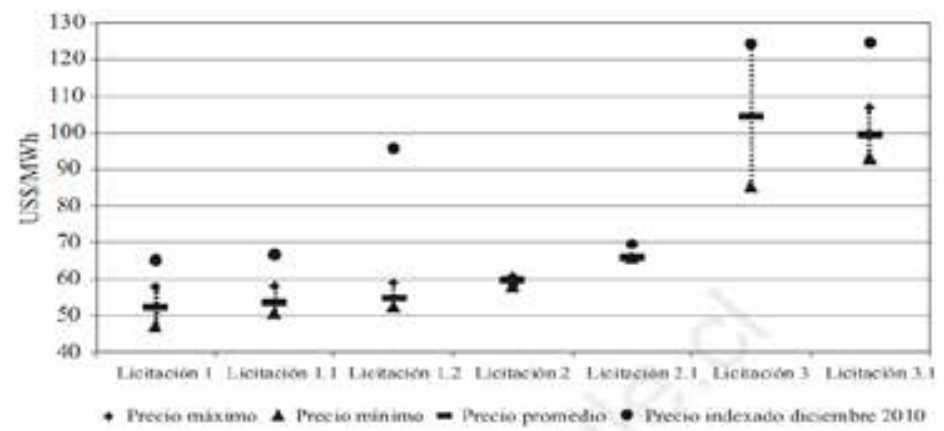

Fuente: Moreno, J., Moreno, R., Rudnick, H. y Mocarquer, S., "Licitaciones para el abastecimiento eléctrico de clientes regulados en Chile: dificultades y oportunidades", en Estudios Públicos, Nº 125, verano 2012, 30 págs.

Nota: Licitación 1 y 1.1: octubre 2006; Licitación 1.2: enero 2007; Licitación 2 y 2.1: octubre 2007 y marzo 2008; Licitación 3 y 3.1: enero 2009 y julio 2009.

50. Supone instalados unos 5.800 MW en ERNC.

51. Esta situación se vio alterada por las indexaciones que experimentaron los precios de los contratos, las que tuvieron una incidencia creciente en el precio final.

52. Por desinterés de las firmas generadoras o por proponer precios que superaban el valor máximo aceptable por las bases de las licitaciones. 
Como se puede apreciar del Gráfico 10 los precios efectivos de las últimas licitaciones superan los US\$120/MWh. Por su parte, las empresas promotoras de las ERNC, agrupadas en la Asociación Chilena de Energías Renovables (ACERA), demostraron que la meta de la moción parlamentaria no solo era posible, sino que además sus precios eran competitivos. El Cuadro 3 explicita el planteamiento de ACERA.

\section{Cuadro 3}

LA META DEL 20/20 ES POSIBLE Y ECONÓMICAMENTE COMPETITIVA

\begin{tabular}{|l|r|r|r|r|r|r|}
\hline \multirow{2}{*}{ Tecnología } & \multicolumn{1}{|c|}{ Pinst } & \multirow{2}{*}{ FP } & Energía & Inv. Unitaria & Inv. Total & Costo Inversión \\
\cline { 2 - 4 } & \multicolumn{1}{|c|}{ MW } & & GWh/año & US\$/MW & MM US\$ & \multicolumn{1}{c|}{ US\$ / MWh } \\
\hline Hidro menor & 1,000 & $50 \%$ & 4,383 & $3,500,000$ & 3,500 & 84 \\
\hline Biomasa & 600 & $60 \%$ & 3,156 & $3,000,000$ & 1,800 & 60 \\
\hline Eólica & 2,500 & $25 \%$ & 5,479 & $2,300,000$ & 5,750 & 110 \\
\hline Geotérmica & 1,000 & $80 \%$ & 7,013 & $5,500,000$ & 5,500 & 82 \\
\hline Solar-Fotovoltaica & 500 & $25 \%$ & 1,096 & $3,100,000$ & 1,550 & 148 \\
\hline Solar-Termoeléctrico & $\mathbf{2 0 0}$ & $\mathbf{2 5 \%}$ & $\mathbf{4 3 8}$ & $\mathbf{4 , 5 0 0 , 0 0 0}$ & $\mathbf{9 0 0}$ & $\mathbf{2 1 5}$ \\
\hline suma & $\mathbf{5 , 8 0 0}$ & $\mathbf{4 2 \%}$ & $\mathbf{2 1 , 5 6 4}$ & $\mathbf{3 , 2 7 5 , 8 6 2}$ & $\mathbf{1 9 , 0 0 0}$ & $\mathbf{9 2}$ \\
\hline
\end{tabular}

Nota: Inversión descontada al $10 \%$ y en 30 años.

Fuente: Escobar, J.I., ACERA, presentación en ELECGAS 2011.

Este cuadro no actualiza a la baja los costos de inversión de algunas tecnologías tales como la energía eólica y, particularmente, la solar fotovoltaica; sin embargo, los valores medios del MWh y, especialmente, los de las tecnologías más maduras comercialmente, indican que ellas son competitivas. Al respecto conviene señalar que ACERA no está solicitando subsidios, sino que se legisle para eliminar algunas de las barreras que le impiden penetrar con fuerza en el sistema y concretar proyectos aprobados por el sistema de evaluación de impacto ambiental (SEIA). A modo de referencia, subastas realizadas por ELECTROBRAS han sido adjudicadas a US\$ 62/MWh para centrales eólicas, algo similar ha ocurrido en Uruguay y México ${ }^{53}$.

- Las ERNC son intermitentes e imprevisibles: Si bien este argumento se aplica básicamente a la energía eólica y solar (aunque esta última no es imprevisible), al hablar genéricamente de las ERNC pareciera válido para todas las fuentes renovables (la energía geotérmica y la biomasa desmienten esta generalización). El Gráfico 11 muestra la intermitencia del abastecimiento de las centrales de pasada

53. En Chile, empresas como Ingenostrum, que está desarrollando tres proyectos fotovoltaicos por un total de 706 MWp, en la Región de Antofagasta, ofrece precios de US\$ 100/MWh. A su vez, diversas compañías están instalando ERNC para su propio consumo, lo que demuestra que estas fuentes satisfacen técnica y económicamente sus requerimientos. Es el caso de CAP, que firmó un acuerdo con SunEdison para construir una planta fotovoltaica de 100 MWp, la que estaría en operación a fines del 2013, y Doña Inés de Collahuasi, que acordó con Solarpack la construcción de una planta fotovoltaica de 25 MWp en Pozo Almonte, la que abastecerá parcialmente sus requerimientos de energía. 
en Chile, intermitencia que el CDEC no ha tenido ningún problema en manejar durante la operación del sistema. Incluso más pronunciadas son las fluctuaciones de la energía embalsada en el período 1994-2011. En términos generales, "se puede afirmar que todas las fuentes de energía eléctrica disponibles en el país tienen asociado un cierto nivel de variabilidad, ya sea por desabastecimiento del energético primario o por indisponibilidad no programada de los equipos (i.e. falla técnica de la central Angamos 2 de 264 MW, con un período de reparación prolongado o la paralización forzosa de las centrales Andina y Hornitos de E-CL en enero de 2013, a dieciséis meses de su puesta en marcha)" ${ }^{n 54}$.

\section{Gráfico 11}

INTERMITENCIA Y ALEATORIEDAD EN EL CASO DE LAS CENTRALES DE PASADA

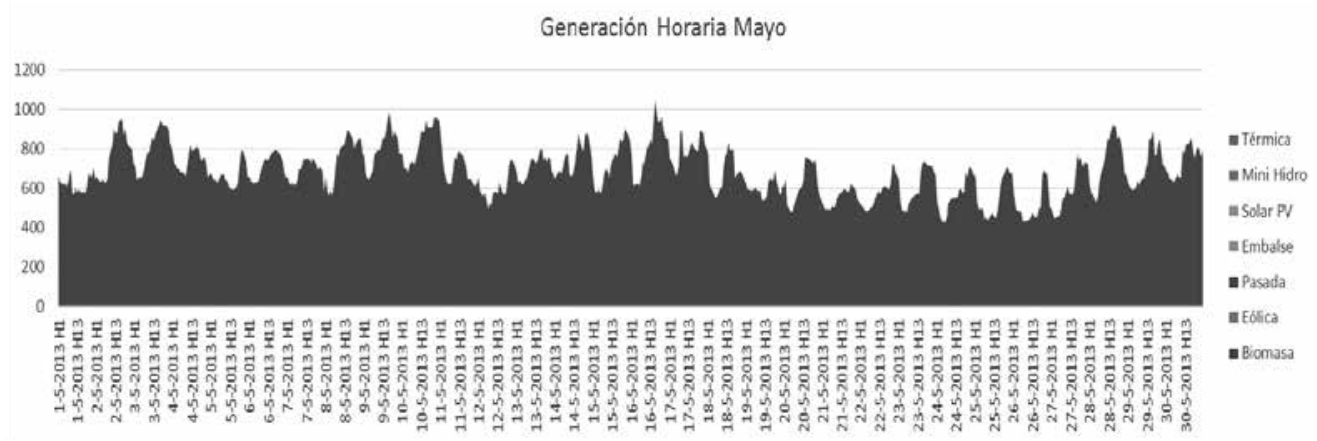

Fuente: Finat, C., director ejecutivo de ACERA, presentación en el Mes de la Energía del Colegio de Ingenieros, 11 de junio de 2013.

Es interesante señalar que cuando se consideran las inyecciones del conjunto de las centrales de ERNC, las fluctuaciones no son tan diferentes a las del sistema eléctrico en su totalidad y es posible apreciar que ninguna fuente deja de generar, es decir, siempre aportan al despacho, una mención especial debe hacerse en el caso de los parques eólicos que, en esa época (2010), estaban prácticamente concentrados en una misma zona (Gráfico 12). Una mayor repartición de las distintas tecnologías en el territorio contribuirá a un despacho sujeto a fluctuaciones menos pronunciadas.

El estudio de Valgesta, citado como fuente del Gráfico 12, simuló la operación del SIC para el año 2010, con y sin participación de las ERNC (3,1\%, debido a la limitante de los contratos) estimándose una reducción promedio semanal del costo medio de operación, como consecuencia del aporte de las ERNC, de 9,93\% y del costo marginal promedio semanal de 3,33\%, el estudio simuló los impactos sobre estos costos en el caso de que el aporte de las ERNC hubiese sido de un 5\%, obteniéndose reducciones de $12,84 \%$ y de $5,14 \%$, respectivamente.

54. Finat, C., director ejecutivo de ACERA, presentación en el Mes de la Energía del Colegio de Ingenieros, 11 de junio de 2013. 


\section{Gráfico 12}

INYECCIÓN SEMANAL DE ENERGÍA DE LAS CENTRALES DE ERNC (SIC), AÑO 2010 (en MWh)

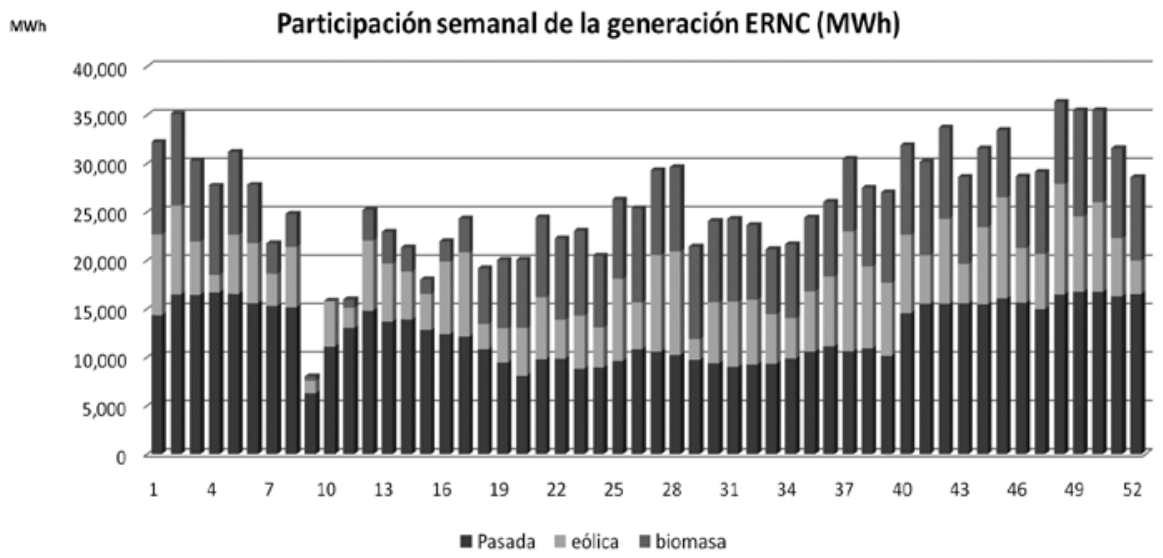

Fuente: Valgesta Energía, Impacto de las energías renovables en la operación del sistema, marzo 2011, 43 págs.

A continuación, se enumeran esquemáticamente las propuestas de política destinada a explotar el importante potencial que presentan las ERNC en Chile:

- Transformar en ley la moción parlamentaria de ampliar a $20 \%$ la meta de las ERNC al año 2025.

- Establecer licitaciones específicas para las ERNC: Se sugiere eliminar la cláusula de los contratos, de manera de asegurar que la meta corresponda con lo que fue el objeto de la ley, y extender a cinco años el tiempo entre la adjudicación de la licitación y el inicio de las inyecciones comprometidas en el contrato.

- Mejorar el acceso al crédito bancario: En la actualidad, los promotores de las ERNC se enfrentan al círculo vicioso de no poder obtener créditos, ya que no cuentan con contratos que aseguren al Banco un flujo de caja que permita pagar el prestamo, y no pueden concursar en las licitaciones porque no tienen los recursos para financiar la inversión requerida para abastecer los requerimientos del contrato.

- Poner en funcionamiento el fondo de cobertura de riesgo en el caso de los proyectos geotérmicos.

- Eliminar las ambigüedades que existen en la Ley Corta II respecto a la conexión de los proyectos a las redes de distribución: A falta de una reglamentación clara, el problema se resuelve mediante una negociación entre las partes, la que normalmente es asimétrica.

- Mejorar el diseño del subsidio al establecimiento de líneas de transmisión que sirvan a un conjunto de proyectos ERNC: Este subsidio no ha sido utilizado por las dificultades del procedimiento y falta de difusión. 
- Definir el reconocimiento de la potencia de los proyectos ERNC: Para ello, se propone que se considere el ingreso por potencia del conjunto de los medios de generación ERNC y, después, se asigne el ingreso de cada generadora.

- Modificación del reglamento de generadores residenciales ("net metering"): El reglamento en negociación actual no rescata el espíritu de la ley, que consideraba que al generador residencial se le pagaría por sus excedentes el mismo precio que él paga a la distribuidora por la energía que recibe de esta, ello mediante un medidor único bidireccional. La propuesta del Ejecutivo supone dos medidores y un pago claramente inferior para la energía que el cliente inyecta en la red.

\section{INCORPORACIÓN DE LAS EXTERNALIDADES EN LA GENERACIÓN TÉRMICA}

El uso de los combustibles fósiles provoca daños importantes en la salud, en la agricultura, en las estructuras construidas por el hombre y en los ecosistemas ${ }^{55}$, los que son, en general, pagados por la sociedad en su conjunto y no por los responsables de los mismos. Resulta ineludible incluir las externalidades provocadas por las fuentes energéticas contaminantes en el costo de los productos o servicios que las utilizan. Recuérdese que el presidente Piñera se declaró partidario de grabar a los "males", sin que hasta el momento ello se haya reflejado en acciones concretas.

En parte, la propuesta gubernamental, incluida en La estrategia nacional de energía $2012-2030^{56}$, presenta un flanco al circunscribir el ecoimpuesto solo a la electricidad y no a todos los tipos de energía, ya que permite argumentar que ella discriminaría en contra de la generación termoeléctrica, lo que es válido, ya que un tributo de este tipo debe gravar también las emisiones contaminantes asociadas al uso de combustibles del resto de las actividades económicas ${ }^{57}$.

Por su parte, quienes se oponen a definir una política en este ámbito argumentan que un impuesto de este tipo produciría incertidumbre entre los inversionistas, atrasos en los planes de desarrollo eléctrico y mayores precios, ignorando que Chile, dentro de Latinoamérica, presenta uno de los más altos precios de la electricidad. Estos mismos sectores señalan que la industria eléctrica prevé invertir US\$ 1.000 millones para cumplir con la reciente norma de emisiones para las centrales termoeléctricas, que apunta a reducir las emisiones de material particulado, dióxido de azufre y óxidos de nitrógeno,

55. La generación hidroeléctrica también provoca impactos socioambientales importantes, pero no serán tratados aquí, ya que ello superaría el alcance de este artículo.

56. Dicha propuesta está sustentada por seis pilares: a) Crecimiento de la Eficiencia Energética, b) Despegue de las ERNC, c) Rol de las energías convencionales: preponderancia al recurso hídrico, d) Nuevo enfoque en transmisión, e) Hacia un mercado más competitivo, f) Avance sostenido en las opciones de interconexión eléctrica regional. Quizás donde se nota más claramente la voluntad gubernamental de avanzar en el logro de los objetivos de la estrategia es en el nuevo enfoque de transmisión.

57. En el fondo, ello proviene de la tendencia de considerar la política energética como sinónimo de política eléctrica. 
olvidando mencionar que la norma dejó fuera los metales pesados, que son tanto o más perjudiciales para la salud de la población. Respetar el límite de emisiones normado significa que se está autorizado para funcionar, pero no implica que no se deban compensar los daños que causan las emisiones remanentes. La inexistencia de los ecoimpuestos subsidia la operación e instalación de las centrales a carbón, puesto que, en las decisiones políticas y de inversión, sus costos se comparan con los de tecnologías limpias que no perjudican en igual medida la salud y el medio ambiente.

La CCTP analizó el efecto sobre la salud, la agricultura, los cursos de agua (ríos y lagos) y las obras civiles, resultante de las emisiones contaminantes que se producen a pesar de la aplicación de la citada norma, planteando no solo la urgencia por imponer un ecoimpuesto, sino que además el monto que se debería cobrar a las fuentes contaminantes por las externalidades negativas que su actividad provoca: US\$ 60/MWh en el caso de la generación a carbón y US\$20/MWh en el caso de la generación con gas natural ${ }^{58}$. Si bien el informe de la CCTP se concentra en el desarrollo sustentable de la industria eléctrica, se asumió que dichos impuestos se deberán aplicar a todo tipo de fuentes emisoras, incorporando estos impuestos al precio de los combustibles, lo que actualmente ocurre con el Impuesto Específico a los Combustibles, que contribuye a paliar, en parte, las externalidades negativas del transporte.

La aplicación de un ecoimpuesto tendrá impactos beneficiosos en distintos ámbitos: a) permitirá sincerar los precios de las distintas alternativas energéticas, b) reducirá los gastos en salud tanto del Estado como de las personas, c) mejorará, a consecuencia de lo anterior, la productividad de la economía al reducir los días perdidos por enfermedad de los distintos agentes productivos, d) reducirá las futuras barreras a nuestras exportaciones, resultantes de una huella de carbono excesiva, y e) favorecerá el desarrollo de una matriz energética más limpia, reforzando las opciones de la eficiencia energética y de las energías renovables no convencionales.

Finalmente, y como un aspecto fundamental que hasta la fecha no ha sido considerado, es necesario destacar que todos los cambios sugeridos no pueden llevarse a cabo a espaldas de la ciudadanía, sino que ellos deben ser la resultante de un proceso participativo real, informado y vinculante que apunte a definir los lineamientos de la nueva política energética y que, en el caso de proyectos de impacto nacional, dicha participación se exprese desde la primeras etapas del proyecto ${ }^{59}$, y no como ocurre actualmente, en que la ciudadanía es consultada cuando se han definido todos los aspecto centrales de este, se han gastado muchos millones de dólares y elaborado complejos y voluminosos informes cuya interpretación y cuestionamiento puede ser realizado por algunos

58. Estos valores fueron definidos a partir de los resultados del informe Análisis del impacto económico y social de la Norma de Emisión para Termoeléctricas preparado, para CONAMA, por Geoaire y KAS ingeniería, y del estudio comparado de los costos externos vigentes en Europa y México. El haber fijado el ecoimpuesto en US\$/MWh es una simplificación; en realidad, se deberían normalizar estos valores en función del rendimiento medio de las tecnologías de generación.

59. Ello supone la posibilidad de cuestionar el emplazamiento, la fuente utilizada, la tecnología preseleccionada y las condiciones de operación. 
pocos especialistas y, peor aún, cada uno de ellos desde su perspectiva disciplinaria sin la posibilidad de integrar los distintos aspectos del proyecto.

El tema de la participación ciudadana en el desarrollo eléctrico es parte de un enfoque más global, ya que se vincula con el derecho de la sociedad de tener injerencia en las decisiones fundamentales que determinan las políticas públicas en distintos ámbitos y que afectan la dignidad y calidad de vida, tanto de las actuales como de las futuras generaciones. El autor de este artículo no se siente capacitado para profundizar en su tratamiento, ya que ello supera largamente los límites de su disciplina. En el caso presente, se sugiere revisar el capítulo correspondiente del documento de la CCTP previamente citado.

\section{CONCLUSIONES}

La reforma del esquema de desarrollo eléctrico nacional, materializada en el DFL $N^{\circ}$ 1 de 1982, y que todavía rige con algunas modificaciones que no alteran su sustancia, entregó al sector privado la facultad de decidir el dónde, el cómo y el cuándo invertir en la expansión del sistema eléctrico, asignándole al Estado un rol subsidiario y con escasa capacidad de regular y fiscalizar. A diferencia del enfoque previo que existía en el país, se privilegió la reducción de los costos del sistema por sobre la seguridad y calidad del suministro. Los resultados de los últimos diez a quince años muestran que, incluso, el objetivo de los precios bajos y de la racionalidad del modelo de desarrollo del sector no se cumplió. Los resultados de treinta años de aplicación de este modelo no son alentadores, ya que el sistema eléctrico nacional es extraordinariamente vulnerable, dependiente, contaminante, carbonizado, caro y altamente concentrado.

La implantación de un modelo que contribuya al desarrollo sustentable, superando las deficiencias mencionadas, requiere de una reforma profunda del marco regulatorio que redefina el rol del Estado en tanto conductor del proceso de cambio, desconcentre el mercado eléctrico, reformule el sistema tarifario y modifique la institucionalidad de los Centros de Despacho Económico de Carga.

El nuevo modelo deberá transformar a la EE y a las ERNC en opciones estratégicas de la política energética, ello supone modificar drásticamente la institucionalidad vigente que rige la política de EE y avanzar en el reemplazo de la actual ley de ERNC, tanto en lo que respecta a las metas como a los mecanismos para lograrlas. Especialmente, en el primer caso, se requiere de significativos recursos humanos, técnicos y financieros para superar los obstáculos que impiden que esta opción se concrete en todo su potencial, como la fuente energética más barata, limpia y segura; por el contrario, el apoyo a las ERNC requiere de instrumentos que le permitan una llegada efectiva al mercado, mediante licitaciones que le aseguren el acceso al crédito bancario, al acceder a contratos de largo plazo y precios estabilizados, ya sea como los actualmente vigentes o, incluso, ligeramente inferiores. Es decir, las empresas involucradas en el desarrollo de las ERNC no demandan subsidios, sino mecanismos que destraben el bloqueo a su desarrollo provocado tanto por la elevada concentración del mercado, 
las cláusulas restrictivas de las licitaciones y las dificultades de acceder a las redes troncales de transmisión.

Se deberán incorporar los costos externos o externalidades, que la producción y uso de la energía provoca, en los precios de las distintas fuentes y que, actualmente, no pagan quienes causan el daño, sino quienes son víctimas de dichos impactos: la sociedad en su conjunto. Ello posibilitará que se sinceren los precios de las distintas alternativas energéticas, que se reduzcan los gastos en salud del Estado y de las personas y que mejore la productividad de la economía, al reducir los días perdidos por enfermedad de los agentes productivos.

Un elemento central de la reforma propuesta es la generación de canales institucionales de participación ciudadana informada y vinculante, de manera que la sociedad tenga la capacidad de incidir efectivamente en la definición de las líneas directrices de la política energética e, incluso, de los macroproyectos que puedan afectar el hábitat de los ciudadanos, los ecosistemas, la herencia cultural de los pueblos originarios, las opciones de desarrollo regional o local, entre otros. 